NASA Technical Memorandum 109135

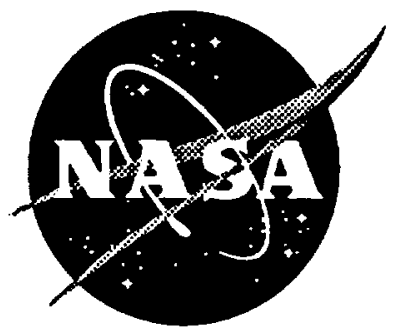

\title{
A Methodology To Predict Damage Initiation, Damage Growth and Residual Strength in Titanium Matrix Composites
}

J. G. Bakuckas, Jr.

Galaxy Scientific Corporation, Pleasantville, New Jersey

W. S. Johnson

Langley Research Center, Hampton, Virginia

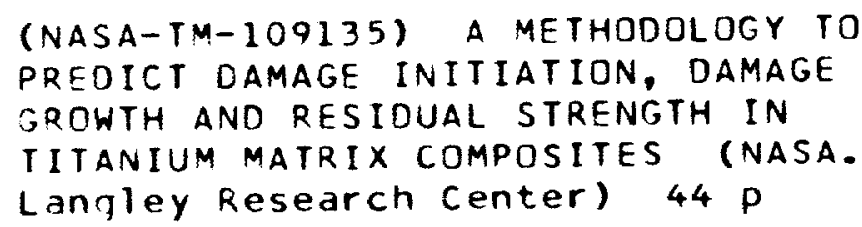

N94-37320

Unclas

$63 / 24 \quad 0017076$

July 1994

National Aeronautics and Space Administration Langley Research Center Hampton, Virginia 23681-0001 



\title{
A Methodology to Predict Damage Initiation, Damage Growth and Residual Strength in Titanium Matrix Composites
}

\author{
J. G. Bakuckas, Jr. ${ }^{1}$ and W. S. Johnson ${ }^{2}$
}

\begin{abstract}
In this research, a methodology to predict damage initiation, damage growth, fatigue life and residual strength in titanium matrix composites (TMC) is outlined. Emphasis was placed on micromechanics-based engineering approaches. Damage initiation was predicted using a local effective strain approach. A finite element analysis verified the prevailing assumptions made in the formulation of this model. Damage growth, namely, fiber-bridged matrix crack growth, was evaluated using a fiber bridging (FB) model which accounts for thermal residual stresses. This model combines continuum fracture mechanics and micromechanics analyses yielding stress-intensity factor solutions for fiber-bridged matrix cracks. It is assumed in the FB model that fibers in the wake of the matrix crack are idealized as a closure pressure, and an unknown constant frictional shear stress is assumed to act along the debond length of the bridging fibers. This frictional shear stress was used as a curve fitting parameter to the available experimental data. Fatigue life and post-fatigue residual strength were predicted based on the axial stress in the first intact $0^{\circ}$ fiber calculated using the FB model and a three-dimensional finite element analysis.
\end{abstract}

Key Words:fiber-matrix debonding, matrix stress intensity factor, continuum fracture mechanics, micromechanics, interfacial frictional shear stress, discrete-continuum relations

1 Senior Research Engineer, Galaxy Scientific Corporation, 2500 English Creek Road, Pleasantville NJ 08232.

2 Senior Research Scientist, NASA Langley Research Center, Hampton VA 23681 


\section{NOMENCLATURE}

\begin{tabular}{|c|c|}
\hline$a, a_{o}$ & Current crack length and unbridged initial crack length, $m$ \\
\hline$d$ & \\
\hline $\begin{array}{l}C, n, m \\
E_{f}, E_{m}\end{array}$ & $\begin{array}{l}\text { Crack growth coefficient constants } \\
\text { Fiber and matrix modulus, MPa }\end{array}$ \\
\hline $\begin{array}{l}E_{L}, E_{T}, G_{L T} \\
F_{a p p}\end{array}$ & $\begin{array}{l}\text { Composite longitudinal, transverse and shear modulus, MPa } \\
\text { Boundary correction factor for applied stress intensity factor }\end{array}$ \\
\hline G & Weight function \\
\hline$K_{t}^{\varepsilon}$ & Strain concentration factor \\
\hline$K_{t}$ & Orthotropic stress concentration factor \\
\hline$\Delta K_{m}$ & Discrete stress intensity factor range in matrix, $\mathrm{MPa} \sqrt{\mathrm{m}}$ \\
\hline$\Delta K_{\text {Comp }}$ & Continuum stress intensity factor range in composite, $\mathrm{MPa} \sqrt{\mathrm{m}}$ \\
\hline$h$ & Distance between parallel cracks, $m$ \\
\hline$\Delta p$ & Range in bridging pressure, $\mathrm{MPa}$ \\
\hline$r$ & Fiber radius, $\mathrm{m}$ \\
\hline$R$ & Hole radius, $\mathrm{m}$ \\
\hline$R_{\text {Comp }}$ & Composite stress ratio $=S^{\min } / S^{\max }$ \\
\hline$R_{m}$ & Matrix stress ratio $=\sigma_{m}^{\min } / \sigma_{m}^{\max }$ \\
\hline$\Delta S$ & Applied stress range, $\mathrm{MPa}$ \\
\hline $\begin{array}{l}\Delta T \\
v_{1}\end{array}$ & $\begin{array}{l}\text { Change in temperature, }{ }^{\circ} \mathrm{C} \\
\text { Fiber volume fractions }\end{array}$ \\
\hline$W$ & Width of specimen, $\mathrm{m}$ \\
\hline$\alpha_{f}, \alpha_{m}$ & Coefficient of thermal expansion for fiber and matrix, $\mathrm{mm} / \mathrm{mm} /{ }^{\circ} \mathrm{C}$ \\
\hline$\Delta \varepsilon_{\text {aff }}$ & Effective strain parameter \\
\hline$\Delta \varepsilon$ & Strain range \\
\hline$\tau$ & Interfacial frictional shear stress, $\mathrm{MPa}$ \\
\hline$v_{L T}$ & Composite Poisson's ratio \\
\hline$\sigma_{f}, \sigma_{m}$ & Axial stress in fiber and matrix, $\mathrm{MPa}$ \\
\hline$\sigma_{f}^{\min }, \sigma_{f}^{\max }$ & Axial stress in the fiber at $S_{\min }$ and $S_{\max }$, respectively, $\mathrm{MPa}$ \\
\hline$\sigma_{f}^{\text {fall }}$ & Failure stress of first intact fiber under static loading, $\mathrm{MPa}$ \\
\hline$\Delta \sigma_{f}^{\text {fail }}$ & Failure stress range in first intact fiber under fatigue loading, $\mathrm{MPa}$ \\
\hline$\sigma_{m}^{\text {Therm }}$ & Axial thermal residual stre \\
\hline
\end{tabular}




\section{INTRODUCTION}

Titanium matrix composites (TMC) have excellent potential as structural materials for elevated temperature applications such as future hypersonic flight vehicles. However, a major problem facing TMC is the lack of a generalized life prediction methodology that can be applied in designs incorporating these advanced materials. The complex damage growth process that evolves in these materials can limit the use of conventional damage tolerance design approaches often used for metals. On the composite microstructural level, damage consists of multiple failure mechanisms including fiber-matrix debonding, fiber breakage and matrix cracking. The interaction and combination of these failure mechanisms can lead to extensive damage process zones having no single dominate crack. In such instances, classical fracture mechanics approaches are not suitable. An additional complexity are thermal residual stresses that are induced in the fiber and matrix during the fabrication process which can have a profound effect on the fracture and fatigue behaviors of TMC. The heterogeneous nature of TMC poses challenges to the development of a damage tolerance design philosophy for this class of materials.

In an effort to address these challenges, a micromechanics-based life prediction methodology is proposed. The effects of applied stress, number of fatigue cycles and specimen geometry (e.g. stress concentrations and notches) on damage initiation, damage growth and residual strength can be determined and could be used as a design limiter for notched TMC. Figure 1 is a flow chart describing this methodology and how it can be used to predict the following fatigue scenarios: (1) initiation of cracks from notches using a local effective strain parameter; (2) growth of matrix cracks to threshold condition where crack arrest occurs based on stress intensity factor in the matrix calculated using a fiber bridging (FB) model; (3) continuous growth of matrix cracks based on stress intensity factor in the matrix using the FB model; (4) specimen life based on the stress in the first intact fiber (unmachined fiber nearest the notch or hole) calculated using the FB model; and (5) post- 
fatigue residual static strength (static strength after fatigue loading) based on the fiber stress calculated using either the FB model or a three-dimensional finite element analysis.

The objectives of this research is to outline the framework for this generalized life prediction methodology. This paper will review research addressing issues of damage initiation, damage growth and post-fatigue residual strength. Emphasis was placed on micromechanics-based approaches. Damage initiation was predicted using a local effective strain approach developed by Hillberry and Johnson [1]. A finite element analysis verified the prevailing assumptions made in the formulation of this model. Next, damage growth and life prediction approaches for fiber bridged matrix crack growth were developed based on a fiber bridging (FB) model. The FB model combines continuum fracture mechanics and micromechanics analyses to derive stress intensity factor solutions of matrix cracks bridged by fibers. Thermal residual stresses were accounted for in this model by Bakuckas and Johnson [2]. The frictional shear stress that is assumed to act along the debond length of the bridging fibers was used as a curve fitting parameter for the available experimental data. Finally, postfatigue residual static strength was predicted based on the axial stress in the first intact $0^{\circ}$ fiber calculated using the FB model developed in [2] and using a three dimensional finite element analysis of Bigelow et al. $[3,4,5]$

\section{EXPERIMENTAL PROCEDURES}

\section{Materials and Specimens}

Two TMC systems were studied in this research, namely, SCS-6/Ti-15-3 and SCS6/Timetal-21S laminates. Both material systems were fabricated by Textron by hot isostatic pressing (HIPing) titanium foils between unidirectional tapes of silicon-carbide (SCS-6) fibers having a diameter of $0.14 \mathrm{~mm}$. In the SCS-6/Ti-15-3 and SCS-6/Timetal-21S laminates, fibers were held in place with molybdenum and titanium-niobium cross weave wires, respectively. The composition of matrix materials used in the SCS-6/Ti-15-3 and SCS6/Timetal-21S laminates, were Ti-15V-3Cr-3Al-3Sn and Ti-15Mo-3Al-2.7Nb-0.2Si, 
respectively. For the SCS-6/Ti-15-3 laminates, the lay-ups studied were $[0]_{8}$ and $[0 / 90]_{S}$ with a range of measured fiber volume fractions $v_{f}$ from 0.33 to 0.36 . For the SCS-6/Timetal-21S laminates, the lay-ups studied were $[0 / 90]_{s}$ and $[0 / 90]_{2 s}$ with a range of measured fiber volume fractions $v_{f}$ from 0.36 to 0.38 . The material properties are listed in Table 1 .

Specimens were machined using a diamond wheel saw into straight-sided coupons with the $0^{\circ}$ fibers in the loading direction. Each specimen was $152.5-\mathrm{mm}$ in length. Center holes having diameters $(d)$ of $6.3 \pm 0.3-\mathrm{mm}$ were drilled ultrasonically in specimens having a width of 19.1-mm. Center slits having lengths $(2 a)$ of $5.08-\mathrm{mm}, 7.62-\mathrm{mm}$ and $8.89-\mathrm{mm}$ and a width of 0.254-mm were machined via electo-discharged machining (EDM) in specimens having a width of $25.4-\mathrm{mm}$. The SCS-6/Ti-15-3 specimens were tested in the as-received condition while the SCS-6/Timetal-21S specimens were heat treated at a temperature of $620^{\circ} \mathrm{C}$ for 8 hours in a vacuum and then furnaced cooled prior to testing. To enhance optical observations and surface replication, the surface of each specimen was polished to obtain a flat and lustrous finish. Thin sheet aluminum end tabs having dimensions $19.1-\mathrm{mm} \times 19.1-\mathrm{mm}$ were bonded on the ends of all specimens in order to prevent grip failure. Information on the specimens tested is listed in Table 2.

\section{Test Procedures}

Testing was conducted using closed-loop servo-hydraulic test machine equipped with water cooled hydraulic grips. Tension-tension fatigue tests were done under load control with $R_{\text {comp }}=0.1\left(S^{\min } / \mathrm{S}^{\max }\right)$ at a frequency of $10 \mathrm{~Hz}$ at both room temperature and an elevated temperature of $200^{\circ} \mathrm{C}$. Results from these tests were generated in previous studies $[3,6,7]$. In these studies, damage initiation and progression were monitored and recorded using several techniques including a closed-circuit television system (CCTV), a long focal length microscopic system, surface and edge replicas, scanning electron microscopy (SEM), and optical microscopy. In addition, the acoustic emission (AE) technique was used where 
emphasis was placed on detecting the occurrence of fiber breakage. Details of the AE set-up and parameters are reported in [8].

\section{ANALYTICAL PROCEDURES}

Figure 1 is a flow chart outlining the micromechanics-based life prediction methodology developed. It was used in this study to determine the effects of applied stress, number of fatigue cycles and specimen geometry (e.g. stress concentrations and notches) on damage initiation, damage growth, fatigue life and residual strength. The method consists of three analysis approaches: (1) local strain model used to predict damage initiation based on the value of the effective strain parameter; (2) fiber bridging model used to evaluated damage growth based on the stress intensity factor in the matrix and used to evaluate fatigue life and post-fatigue residual strength based on the stress in the first intact fiber, and; (3) a threedimensional finite element model used to predict the virgin static and post-fatigue residual static strengths based on the stress in the first intact fiber. These three approaches were developed in previous studies and were combined in this paper to make up the framework for a life prediction methodology. A brief description of these three approaches and the application to damage initiation, damage growth, fatigue life, and residual strength are discussed next.

\section{Matrix Crack Initiation}

A procedure to predict the initiation of damage in the form the matrix cracks was introduced in [1]. In the approach, an effective strain parameter was used which includes thermal residual stresses and stress concentrations:

$$
\Delta \varepsilon_{e f f}=\sqrt{\left(K_{t} \varepsilon_{\max }+\frac{\sigma_{m}^{\text {Therm }}}{E_{m}}\right) \frac{K_{t} \Delta \varepsilon}{2}}
$$

where $K_{t}, \varepsilon_{\max }, \sigma_{m}^{\text {Therm }}, E_{m}$, and $\Delta \varepsilon$ are the orthotropic stress concentration factor, the maximum applied strain, the axial matrix thermal residual stress in the $0^{\circ}$ plies, the matrix modulus, and the applied strain range, respectively. It is assumed in this model that the strain 
in the fiber, matrix, and composite are compatible and that the strain concentration factor in the matrix, $K_{t}^{\varepsilon}$, is equal to the orthotropic (composite) stress concentration factor, $K_{t}$.

The axial matrix thermal residual stress, $\sigma_{m}^{\text {Therm }}$, induced during the fabrication process was calculated using the VISCOPLY code [9], a micromechanics based model. The thermoviscoplastic properties of the constituents used in the calculation of $\sigma_{m}^{\text {therm }}$ are reported in [9] for SCS-6/Ti-15-3 laminates and in [10] for SCS-6/Timetal-21S laminates. In order to include thermal residual stresses in the calculations, the composite fabrication process was analytically simulated by modeling the cool down cycle from an assumed stress-free temperature to room temperature. A stress-free temperature of $555^{\circ} \mathrm{C}$ was used for the SCS-6/Ti-15-3 laminates and $620^{\circ} \mathrm{C}$ was used for the SCS-6/Timetal-21S laminates. For SCS-6/Ti-15-3 laminates, it was assumed that the stress-free condition occurs at one half the melting temperature of the titanium matrix, that is, at $555^{\circ} \mathrm{C}$. For the SCS-6/Timetal-21S laminates, it was assumed that the residual stresses were removed during the heat treatment cycle at a temperature of $620^{\circ} \mathrm{C}$. Values of $\sigma_{m}^{\text {Therm }}$ induced during cool-down of the composite fabrication are listed in Table 1.

The effective strain parameter as a function of cycles to failure (final fracture) for the Ti-15-3 matrix material was determined in [1] and is shown in Figure 2. The solid line is a curve fit to the experimental data. For a notched composite with matrix thermal residual stresses, the number of cycles to matrix crack initiation can be predicted by comparing the effective strain parameter defined by Equation (1) with the solid line in Figure 2.

\section{Finite Element Analysis}

A finite element analysis was conducted in this research to verify the prevailing assumptions made in the effective strain approach. The assumptions made in this model (Equation 1) are the following: (1) strain in the fiber, matrix and composite are compatible, (2) the orthotropic stress concentration factor is the same as the strain concentration factor for the fiber, matrix and composite. Thus, the stress concentration calculated using a anisotropic continuum analysis is assumed to be equivalent to the strain concentration in the matrix. A 
concern with this assumption is that the local stress concentrations that occurs near the ends of discrete machined fibers, particularly for hole configurations, are not accounted for. In some instances, cracks have been observed to initiate and grow as shown in Figure 3 where the initiation site is in the region of a machined fiber end. In order to determine the severity of the stress concentration factor around discrete fiber ends along the hole boundary, a twodimensional finite element analysis was conducted for a unidirectional SCS-6/Timetal-21S monolayer having a fiber volume fraction, $v_{f}=0.36$, and containing a center hole, $d / W=$ 0.33 .

The finite element model used is shown in Figure 4 which consists of a global region and a local heterogeneous region. The global region was used to model the specimen geometry to which the far-field loads were applied and was treated as an orthotropic elastic continuum whose properties were calculated from the constituent properties using the rule-ofmixtures. The local heterogeneous region was used to conduct the micromechanics analysis near the center hole. In this region, the fiber and matrix was modeled as distinct zones using their respective neat properties. The constitutive properties used in the finite element analysis of the SCS-6/Timetal-21S monolayer are given in Table 1.

The entire finite mesh consisted of 2588 elements and 10,581 nodes. Nine-noded isoparametric elements with $3 \times 3$ Gauss numerical integration was used. Thermal residual stresses were included in the analysis by simulating the cool-down cycle from an assumed stress-free temperature of $620^{\circ} \mathrm{C}$ to room temperature, as described previously. Then a mechanical load was applied incrementally up to $700 \mathrm{MPa}$ along the top row of nodes.

The distribution of the Von-Mises effective stresses in the matrix is shown in the stress contours in Figure 5. As shown in this figure, stress concentrations do exist in the matrix in the vicinity of the machined fiber ends. For the sake of clarity, not all contours are labeled for the matrix material between the first and second cut fibers and the second and third cut fibers. A detailed stress contour for the matrix between the first (back) cut fiber and second (front) cut fiber is shown in Figure 6 indicates that the stress builds-up behind the second (front) cut 
fiber. Similar results were obtained for the matrix material between the remaining cut fibers, Figure 5; the stress builds-up behind the front cut fibers. Despite these local stress concentrations, the maximum stress and strain concentration still occurs at Location $A$ in Figure 5. Thus, the center hole is the primary stress concentration while the machined fiber ends are secondary stress concentrations.

The local strain concentration factor in the matrix is defined as:

$$
K_{l}^{\varepsilon}=\frac{\varepsilon_{\text {axial }}^{\text {local } \max }}{\varepsilon_{\text {acial }}^{\text {global }}}
$$

where $\varepsilon_{\text {axial }}^{\text {local max }}$ is the maximum local axial strain (at Location A, Figure 5) and $\varepsilon_{\text {axial }}^{\text {global }}$ is the remote global axial strain. For an elastic analysis from the initial load increment, $K_{t}^{\varepsilon}=$ 3.81. The global stress concentration factor for a hole in an orthotropic continuum is defined [11] as:

$$
K_{1}=\left(1+\sqrt{\frac{E_{L}}{G}-2 v_{L T}+2 \sqrt{\frac{E_{L}}{E_{T}}}}\right) \alpha
$$

The terms in this equation are the laminate properties as defined in the nomenclature section. The term $\alpha$ is the finite width correction factor. In this study, the finite width correction factor for isotropic material was used [12]:

$$
\alpha=\frac{2+\left(1-\frac{d}{W}\right)^{3}}{3\left(1-\frac{d}{W}\right)}
$$

For the composite analyzed, $K_{t}=3.83$ which is in excellent agreement with the strain concentration factor $\left(K_{t}^{\varepsilon}\right)$ calculated from the discrete finite element analysis and, therefore, can be used in the definition of the local effective strain given by Equation (1). 


\section{Matrix Crack Growth}

Methods to evaluate matrix crack growth was introduced in several studies using fiber bridging (FB) models [13-15]. The application of these FB models to analyze damage growth in unidirectional TMC was demonstrated in [6]. The frictional (fiber-matrix interface) shear stress term assumed in these models was used as a fitting parameter to crack growth data. It was shown in this study that the FB models do provide an engineering tool for interpreting crack growth data in this class of materials. However, the values of the frictional shear stress term used to evaluate crack growth data varied with several parameters including the applied load and crack length. Further developments of fiber bridging analysis was realized when thermal residual stresses were considered [2]. It was shown in [2] that a single value of frictional shear stress was sufficient to evaluate the crack growth data for a given material system, lay-up and applied temperature. While these studies are encouraging, the FB models still lack true predictive capabilities because the frictional shear stress term must be determined experimentally.

Fiber bridged matrix crack growth was analyzed using the approach outlined in [2]. In that study, crack growth behavior was evaluated according to a version of the power law function introduced by Walker which includes R-ratio effects [16]:

$$
\frac{d a}{d N}=C \cdot\left(\frac{\Delta K_{m}}{\left(1-R_{m}\right)^{(1-m)}}\right)^{n}
$$

where $C, n$, and $m$ are material constants for the neat matrix material, $R_{m}$ is the local stress

ratio in the matrix $\left(R_{m}=\sigma_{m}^{\min } / \sigma_{m}^{\text {max }}\right)$ and $\Delta K_{m}$ is the Mode I stress intensity factor range in the matrix. By using Equation (5), thermal residual stresses can be included in the analysis through the quantities $R_{m}$ and $\Delta K_{m}$ as described next. 


\section{Calculation of $\mathbf{R}_{\mathbf{m}}$}

The stress ratio in the matrix $\left(R_{m}=\sigma_{m}^{\min } / \sigma_{m}^{\text {max }}\right)$ was calculated using the VISCOPLY code [9]. After the composite fabrication simulation, a global mechanical load from $S^{\text {min }}$ to $S^{\max }$ was applied, and the corresponding stresses in the matrix in the $0^{\circ}$ plies were calculated. Using these values of stress, the value of $R_{m}$ in the matrix in the $0^{\circ}$ plies was calculated. Values of $R_{m}$ are listed in Table 2 for each specimen tested. As revealed by the results in Table 2, the values of $R_{m}$ were considerably higher than the value of the applied R-ratio ( $R_{\text {comp }}$ $=0.1$ ). Thus, the value of $R_{\text {comp }}$ does not represent the actual stress ratio in the matrix and the local $R_{m}$ values listed in Table 2 should be used in the analysis.

\section{Calculation of $\Delta \mathrm{K}_{\mathrm{m}}$}

The stress intensity factor range in the matrix, $\Delta K_{m}$, was calculated using an FB model implemented with thermal residual stresses. It is assumed in this model that fiber-matrix debonding takes place as a matrix crack progresses past the fibers. The intact fibers in the wake of the matrix crack are idealized as a crack bridging pressure, $\Delta p$. An unknown but constant frictional shear stress, $\tau$, is assumed to act along the debond length of the bridging fibers. A continuum fracture mechanics analysis and a micromechanical analysis are combined using discrete-continuum relations to obtain stress intensity factor solutions for fiber bridging matrix cracks of arbitrary size.

In the calculation of $\Delta K_{m}$, the crack opening displacement in terms of the bridging pressure obtained from the micromechanical analysis and the continuum fracture mechanics analysis are combined using discrete-continuum relations to yield a single non-linear integral equation in terms of the bridging pressure. Solving for the bridging pressure, $\Delta K_{m}$ can be determined. Assuming the discrete-continuum relations in [15], the stress-intensity factor in the matrix is:

$$
\Delta K_{m}=\Delta S \sqrt{\pi a} F_{a p p}-2 \int_{a_{0}}^{a} \Delta p G(x, a, R, W) d x
$$


In this equation, $\Delta S$ is the applied far-field stress, $F_{a p p}$ is the applied stress boundary correction factor, $a_{o}$ is the initial unbridged crack length (hole radius or notch length). In addition, the term $G(x, a, R, W)$ is the weight function for the bridging stress intensity factor range. Details on the calculation of can be found in [2].

\section{Fatigue Life}

A procedure to predict fatigue life is proposed in this study based on the axial stress in the first intact fiber calculated using the FB model. The axial stress in the fibers is approximated in terms of the bridging pressure $(\Delta p)$ and the fiber volume fraction $\left(\nu_{f}\right)$ :

$$
\Delta \sigma_{f}=\frac{\Delta p}{v_{f}}
$$

This equation is valid for fibers closely spaced relative to the crack length. The bridging pressure is calculated using the aforementioned fiber bridging model. When the stress in the first intact fiber reaches a critical value, failure of that fiber occurs. During fatigue loading of TMC, catastrophic fracture of a specimen typically occurs shortly after the onset of fiber breakage. By determining the stress in the first intact fiber, the conditions under which a specimen will fail, namely, the loading conditions (applied load and number of cycles) and the specimen configuration (hole diameter and crack length) can be predicted.

For this purpose, the onset of fiber breakage was monitored and recorded in several cross-ply SCS-6/Timetal-21S specimens containing center holes using the AE technique. A detailed description of the AE test set-up and parameters used is provided in [8]. Briefly, AE events having high amplitudes (i.e. greater than or equal to $99 \mathrm{~dB}$ ) were associated with fiber breakage.

The onset of fiber breakage was also determined from the crack growth characteristics. A schematic of the crack length as a function of number of cycles is shown in Figure 7. For this example, the crack growth is characterized by three regions: (1) initiation and growth, (2) slow growth/crack arrest, and; (3) rapid crack growth. After the initial region, the rate of 
crack growth decreases due to the fiber bridging phenomena. The number of fibers bridging the crack increases as the crack length increases thereby reducing the stress-intensity factor in the matrix. As the crack extends, the stress in the bridging fibers increases. Under certain conditions, the stresses in the fibers may become sufficiently high to cause fiber breakage to occur resulting in the rapid crack growth in the third region. In this study, the onset of fiber breakage is assumed to occur at the "knee" of the crack growth curve between the second and third regions, Figure 7.

Using the AE technique and the characteristics of the crack growth curve, the conditions (i.e.: specimen geometry, crack length, applied load, number of cycles, etc.) under which fiber breakage occurs was determined for several specimens. Using these conditions as input parameters, the failure stress range for the first intact fiber, $\Delta \sigma_{f}^{\text {fail }}$, was calculated using the FB model and was used as a failure criterion to predict fatigue life. These failure stresses are the range values $\left(\Delta \sigma_{f}^{f a l}=\sigma_{f}^{\max }-\sigma_{f}^{\min }\right)$ between $S^{\min }$ and $S^{\max }$ and are listed in Table 3 .

\section{Post -Fatigue Residual Strength}

The post-fatigue residual strength was predicted using two approaches: (1) a fiber bridging model, and; (2) a three dimensional finite element program, PAFAC [17]. The axial stress in the $0^{\circ}$ fiber next to the notch (first intact fiber) was predicted as a function of applied load. The composite strength was assumed to be the applied load at which the axial stress in the $0^{\circ}$ fiber next to the hole reached the fiber strength.

Selection of the approach used to predict the post-fatigue residual strength depends on the characteristics of the damage process zone near the notch. For damage classified as selfsimilar, mode I matrix crack growth, the fiber bridging model is suitable. The FB models are applicable to the analysis of SCS-6/Timetal-21S laminates where the damage is primarily a single mode I matrix crack. The fiber bridging analysis was previously described. The critical fiber strength, $\sigma_{f}^{\text {fail }}$, used to determine the onset of fiber breakage in SCS-6/Timetal21S during static loading is listed in Table 3. These failure stresses are absolute values and are 
lower than the ranges values obtained under fatigue loading. Under fatigue loading, the fiber stresses at the minimum applied load, $\sigma_{f}^{\text {min }}$, is compressive due to the thermal residual stresses. Consequently, the fiber stress range under fatigue loading, $\Delta \sigma_{f}^{\text {fal }}$, is higher than the absolute fiber stress under static loading, $\sigma_{f}^{\text {fail }}$.

In TMC where extensive damage process zones develop, such as in SCS-6/Ti-15-3, a more robust approach must be used such as a three-dimensional finite element analysis. Details of this approach are outlined in [3-5]. Briefly, a three-dimensional finite element code PAFAC [17], is used to calculate the fiber stresses. The damage that evolves during fatigue loading, namely, matrix cracking and fiber-matrix debonding, are analytically simulated by using reduced stiffness properties of the matrix material.

\section{RESULTS AND DISCUSSION}

The aforementioned fatigue crack growth methodology was used to determine the effects of applied stress, number of fatigue cycles, applied temperature and specimen geometry (e.g. stress concentrations and notches) on damage initiation, damage growth, fatigue life and residual strength in TMC as discussed in the following sections.

\section{Matrix Crack Initiation}

Using Equation (1), the effective strain parameter versus the number of cycles to matrix crack initiation is plotted in Figure 8 for the SCS-6/Ti-15-3 laminates tested in $[1,3]$. In this figure, $\mathrm{CH}$ and DEN designate center hole and double edge notched specimens, respectively. The solid line is the baseline curve for the matrix material (same as that shown in shown Figure 2). Experimentally, matrix crack initiation was assumed when the crack length reached between $0.3-\mathrm{mm}$ and $0.5-\mathrm{mm}$. As shown in Figure 8, by using Equation (1), the experimental data are consolidated along the baseline curve indicating the effective strain parameter can be used to predict crack initiation in the matrix reasonably well. 


\section{Matrix Crack Growth}

The matrix crack growth behavior observed in the two TMC systems was analyzed using the FB model implemented with thermal residual stresses [2]. The frictional shear stress term, $\tau$, in the FB model was used as a curve-fitting parameter to matrix crack growth data, reduced using the crack growth law defined by Equation (5). Results are presented in the subsequent sections. The effects of thermal residual stresses on the values of $\tau$ used in fiber bridging analysis are also discussed.

\section{Calculated Crack Growth Curves}

The crack length as a function of number of cycles was calculated and plotted in Figures 9 through 12 using values of $\tau$ which best-fit the experimental results for the two material systems having various external load and geometry conditions. The discretecontinuum relations developed by Marshall, Cox and Evans (MCE) [13] were used in the calculations. As shown for each figure, a good agreement was obtained between the experiments (open symbols) and calculations (filled symbols) using a single value of the frictional shear stress.

Of particular interest is the results presented in Figure 12 showing the crack length as a function of the number of cycles at room temperature and at an elevated temperature of $200^{\circ} \mathrm{C}$ for two center notched specimens of $[0 / 90]_{\mathrm{S}}$ SCS-6/Timetal-21S. As shown in the figure,

good agreement was obtained between experiments (open symbols) and the calculations (filled symbols) using the values of $\tau=50 \mathrm{MPa}$ and $15 \mathrm{MPa}$ for the room temperature and elevated temperature test results, respectively. The difference in the calculated crack growth behavior at the two temperatures is due primarily to the differences in thermal residual stress states which effects the calculated values of $R_{m}$ and $\Delta K_{m}$.

If the mechanical properties of the matrix are assumed to be identical at both temperatures, only $R_{m}$ and $\Delta K_{m}$ affect the crack growth rate defined by Equation (5). At elevated temperatures, the axial thermal residual stress in the matrix $\sigma_{m}^{\text {Therm }}$ is lower than at 
room temperature which results in lower values of $R_{m}$. For the room and elevated temperature tests, the calculated local R-ratios in the matrix were $R_{m}=0.75$ and $R_{m}=0.64$, respectively. From Equation (5), for a given value of $\Delta K_{m}$, the crack growth rate increases with an increase in the value of $R_{m}$. Based solely on the values of $R_{m}$ for the two test conditions, the crack growth rate should have been higher for the room temperature test than the elevated temperature test. Results shown in Figure 12, however, show the opposite trend; the crack growth rate data was higher for the elevated temperature test compared to the room temperature test.

Another factor affecting the crack growth rate is the stress-intensity factor range $\Delta K_{m}$. Thermal residual stresses affect the value of $\Delta K_{m}$. The lower value of $\tau$ for the elevated temperature test translated into a higher value in the stress-intensity factor range as shown in Figure 13. At the elevated temperature, the value of $\Delta K_{m}$ was higher than at room temperature. Using the crack growth law defined by Equation (1), for a given value of $R_{m}$, the crack growth rates increases with an increase in the value of $\Delta K_{m}$ which agrees with the results shown in Figure 12. As a result of the lower thermal residual stresses at the elevated temperature test, the value of $\Delta K_{m}$ increased while the value of $R_{m}$ decreased. The lower values of $\tau$ for the elevated temperature results suggests that the radial thermal residual stresses acting across the debonded fiber-matrix interfaces in the $0^{\circ}$ plies were lower. These radial stresses "choke" the fibers which enhances the shear transfer between the fiber and matrix. By lowering the radial thermal stresses, the amount of shear transfer and displacement constraint between the fiber and matrix were lowered thereby increasing the stress-intensity factor. The increase in the value of $\Delta K_{m}$ had a more profound effect on the crack growth rate than the decrease in the value of $R_{m}$.

\section{Effect of Thermal Residual Stress on the Frictional Shear Stress}

The effect of thermal residual stresses on fiber bridging analysis is revealed in the values of the frictional shear stress term required to reduce the crack growth data which are 
listed in Table 2. The values of $\tau$ listed in this table were determined using the discretecontinuum relations developed by McMeeking and Evans (ME) [15] with and without thermal residual stress. For the unidirectional SCS-6/Ti-15-3 specimens tested in [6], the value of $\tau$ required to fit crack growth data varied from $12 \mathrm{MPa}$ to $41 \mathrm{MPa}$ when thermal residual stresses are neglect (i.e. original fiber bridging analysis). On the other hand, when thermal residual stresses were included in the analysis, only a single value of frictional shear stress, $\tau$ $=60 \mathrm{MPa}$, was required to curve-fit the data. Thus, the scatter in the value of $\tau$ was reduced significantly by considering thermal residual stresses in the fiber bridging analysis. In fact, for a given material system, lay-up and temperature, a single value of $\tau$ was sufficient to analyze the crack growth data. Thermal residual stresses are an important factor overlooked in the original formulations of the FB models.

\section{Fatigue Life}

Using the values of frictional shear stress used to evaluate the crack growth data presented in the pervious section, the fatigue life was estimated based on the stress in the first intact fiber. The critical value of stress in the fiber at which fiber breakage occurred was first determined for several specimens of cross-ply SCS-6/Timetal-21S. For these specimens, the Acoustic Emission (AE) technique and the characteristics of the crack growth curve were used to determine the conditions (i.e.: specimen geometry, crack length, applied load, number of cycles, etc.) under which fiber breakage occurred as described previously. Using these conditions as input parameters, the value of stress in the first intact fiber when fiber breakage occurs was calculated for both static and fatigue applied loadings using the FB model. Results are presented in Table 3. As shown, the value of the axial stress in the first intact fiber was nearly a constant value for the specimens listed. In this study, the average value of the stresses listed in Table 3 was used as a critical value to determine the onset of fiber breakage. Under fatigue loading conditions, the value of stress used was $2500 \mathrm{MPa}$ and under static loading conditions, the value used was $2000 \mathrm{MPa}$. 
Having the critical value of fiber stress, the life prediction methodology was applied to a $[0 / 90]_{2 \mathrm{~s}}$ SCS-6/Timetal-21S laminate containing a center hole subjected to $S_{\max }=200 \mathrm{MPa}$ and $R_{\text {Comp }}=0.1$. The crack length as a function of the number of cycles was monitored and is plotted in Figure 11 along with the calculation made using the FB model and a value of $\tau=$ $50 \mathrm{MPa}$. Crack growth was recorded up to 200,000 cycles. This specimen failed after 222,600 cycles. The stress in the first intact fiber as a function of the number of fatigue cycles was calculated and plotted in Figure 14. As shown in the figure, the stress in the first intact fiber reaches the average critical value (2500 MPa) after 285,000 cycles.

\section{Post -Fatigue Residual Strength}

The post-fatigue residual strength was evaluated in two cross-ply TMC laminates containing center holes, namely, in a SCS-Ti-15-3 specimen and a SCS-6/Timetal-21S specimen. The SCS-6/Ti-15-3 specimen had been subjected to $S_{\max }=250 \mathrm{MPa}$ for 200,000 cycles during which extensive matrix cracking occurred [3]. This specimen was loaded quasistatically in tension to failure and a residual strength of $325 \mathrm{MPa}$ was measured.

The SCS-6/Timetal-21S specimen had been subjected to $S_{\max }=150 \mathrm{MPa}$ for 200,000 cycles during which two symmetric cracks grew from the hole. This specimen was then loaded quasi-statically in tension to failure and a residual strength of $350 \mathrm{MPa}$ was measured. The $\mathrm{AE}$ technique was used to determine the occurrence of fiber breakage. For this specimen, the number of high amplitude events, that is, AE events having an amplitude greater than $98 \mathrm{~dB}$, associated with fiber breakage, is plotted in Figure 15 as a function of the applied load. As shown, fiber breakage occurs at an applied load of $180 \mathrm{MPa}$. The number of high amplitude events increases up to failure at $350 \mathrm{MPa}$. This indicates that stable fiber breakage occurred prior to catastrophic fracture. From the onset of fiber breakage, an increase in applied load was required for subsequent fiber breakage's. 


\section{Fiber Bridging Analysis}

The FB model was used to evaluate the post-fatigue residual strength for SCS6/Timetal-21S specimen. Since the fatigue damage that occurred in SCS-6/Timetal-21S specimen can be considered as mode I self-similar crack growth, the application of the FB model in the analysis was suitable. The axial stress in the first intact fiber as a function of the applied load was calculated. The onset of set of fiber breakage was assumed to occur when the stress in the first intact fiber equaled the critical value of $2000 \mathrm{MPa}$. The critical value was calculated as described previously. Using the FB model, the stress in the first intact fiber reaches the critical value at an applied load of $235 \mathrm{MPa}$. Using the $\mathrm{AE}$ technique, the emission of high amplitude events associated with fiber breakage occurred at $180 \mathrm{MPa}$. A comparison is shown in Figure 15. While both these values are in agreement, this specimen failed catastrophically at $350 \mathrm{MPa}$. This indicates that the occurrence of first fiber breakage may not be a good indicator of post-fatigue residual strength for the SCS-6/Timetal-21S. The results shown in Figure 15 suggest that a stable fiber breakage occurred prior to catastrophic fracture.

\section{PAFAC Analysis}

A three dimensional finite element analysis (PAFAC) was used to predict the virgin static and post-fatigue residual strengths in cross-ply SCS-6/Ti-15-3 laminates containing center holes. For the virgin specimen, the constituent properties shown in Table 1 were used. In addition, fiber-matrix debonding in the $90^{\circ}$ plies was modeled as described in [5]. The damage that occurred in fatigued specimen was quite extensive and widespread consisting of multiple matrix cracks and fiber-matrix debonding. This damage was simulated using a reduced matrix modulus as described in [3].

The axial stress in the $0^{\circ}$ fiber next to the center hole as a function of the applied stress is plotted in Figure 16 for both cases. The horizontal line indicates the assumed fiber strength of $4400 \mathrm{MPa}$, and the two vertical lines show the experimental strengths of the two conditions. 
The fiber strength was calculated from the measured strain to failure of an $[0 / 90]_{S}$ unnotched specimen $\left(\varepsilon_{\mathrm{f}}^{\text {ult }}=0.0011\right)$ multiplied by the fiber modulus (400 GPa). As shown in Figure 16 , the applied stress at which the $0^{\circ}$ fiber stress equals the fiber strength corresponds closely to the measured strength for both conditions. Using the axial stress in the $0^{\circ}$ fiber next to the center hole as the criterion for laminate failure, the predicted strengths for the virgin and postfatigue conditions were $483 \mathrm{MPa}$ and $301 \mathrm{MPa}$, respectively. Both predictions are within $8 \%$ of the experimental values.

\section{SUMMARY}

In this study, a micromechanics-based life prediction methodology was presented and used to determine the effects of applied stress, number of fatigue cycles and specimen geometry on damage initiation, damage growth and residual strength in notched Titanium Matrix Composite (TMC). This methodology was applied to two TMC systems, namely, SCS-6/Ti-15-3 and SCS-6/Timetal-21S.

Damage initiation was predicted using a local effective strain approach. A finite element analysis of a SCS-6/Timetal-21S monolayer containing a center hole verified the prevailing assumptions made in the formulation of this model. The finite element analysis showed that the primary stress concentration was due to the center hole and that the local stress concentrations due to machined fiber ends were secondary. Using the effective strain approach, the conditions under which matrix cracks initiated were predicted.

Damage growth analysis of fiber bridged matrix cracks was developed based on a fiber bridging (FB) model which accounts for thermal residual stresses. The FB model combines continuum fracture mechanics and micromechanics analyses to derive stress intensity factor solutions of matrix cracks bridged by fibers. The unknown constant frictional shear stress assumed in this model was used in this study as a curve fitting parameter to the available experimental data. For a given material system, lay-up and applied temperature, a single 
value of frictional shear stress was sufficient to accurately model the matrix crack growth behavior.

The fatigue life was predicted based on the axial stress in the first intact $0^{\circ}$ fiber calculated using the FB model. The critical value of stress at which fiber breakage occurred was first determined for several specimens. For these specimens, the Acoustic Emission (AE) technique and the characteristics of the crack growth curve were used to determine the conditions under which fiber breakage occurred. Using these conditions as input parameters, the value of stress in the first intact fiber when fiber breakage occurs was calculated using the FB model and was found to be nearly a constant value. This critical value was then used to predict the onset of fiber breakage during fatigue loading in a subsequent specimen. It was assumed that fatigue life is given by the number of fatigue cycles at which fiber breakage initiates. There was approximately a $22 \%$ difference between the observed and predicted fatigue lives.

The post-fatigue residual strength was predicted based on the axial stress in the first intact $0^{\circ}$ fiber calculated using either the FB model and a three-dimensional finite element analysis, depending on the classification of fatigue damage. The fatigue damage developed in the SCS-6/Timetal-21S laminates can be idealized as a mode I, self-similar crack. For this case, the fracture mechanics-based approaches are appropriate and the FB model was used. Using the FB model, the predicted applied load causing the onset of fiber breakage was in agreement with $\mathrm{AE}$ results. There was approximately a $23 \%$ difference in the results.

The virgin static and post-fatigue residual strength was predicted for cross-ply SCS6/Ti-15-3 laminates containing a center hole using a three-dimensional finite element analysis. The fatigue damage that occurred was quite extensive and widespread consisting of multiple matrix cracks and fiber-matrix debonding. This damage was simulated using a reduced matrix modulus. Using the axial stress in the $0^{\circ}$ fiber next to the center hole as the criterion for laminate failure, the predicted strengths were within $8 \%$ of the experimental values. 


\section{Acknowledgments}

The first author gratefully acknowledges the support extended by the National Research Council, Washington, DC., through their Associateship Program, while conducting this research.

\section{REFERENCES}

[1] Hillberry, B. M. and Johnson, W. S., "Prediction of Matrix Fatigue Crack Initiation in Notched SCS-6/Ti-15-3 Metal Matrix Composites," Journal of Composites Technology \& Research, Vol. 14, No. 4, 1992, pp. 221-224.

[2] Bakuckas, J. G., Jr., and Johnson, W. S., "Influence of Thermal Residual Stresses on the Fiber Bridging Analysis of Titanium Matrix Composites," NASA TM 109082, February 1994.

[3] Bakuckas, J. G. Jr., Johnson, W. S., and Bigelow, C. A., "Fatigue Damage in CrossPly Titanium Metal Matrix Composites Containing Center Holes," Journal of Engineering Materials and Technology, Vol. 115, October 1993, pp. 404-410.

[4] Bigelow, C. A., "A Micromechanics-Based Strength Prediction Methodology for Notched Metal-Matrix Composites," Composites, Vol. 24, No. 2, 1993, pp. 113-121.

[5] Bigelow, C. A., and Johnson, W. S, "Effect of Fiber-Matrix Debonding on Notched Strength of Titanium Matrix Composites," Fracture Mechanics 23rd Symposium, ASTM 1189, Ed. R. Chona, 1993, pp. 696-712.

[6] Bakuckas, J. G., Jr., and Johnson, W. S., "Application of Fiber Bridging Models to Fatigue Crack Growth in Unidirectional Titanium Metal Matrix Composites," Journal of Composites Technology and Research, Vol. 15, No. 3, Fall 1993, pp. 242-255.

[7] Bakuckas, J. G., Jr., and Johnson, W. S., "Modeling Fatigue Damage in Cross Ply Titanium Matrix Composites," NASA TM 108988, 1993.

[8] Bakuckas, J. G. Jr., Prosser, W. H., and Johnson, W. S., "Monitoring Damage Growth in Titanium Matrix Composites Using Acoustic Emission," Journal of Composite Materials, Vol. 28, No. 4, 1994, pp. 305-328.

[9] Mirdamadi, M., Johnson, W. S., Bahei-El-Din, Y. A., and Castelli, M. G., "Analysis of Thermomechanical Fatigue of Unidirectional Titanium Matrix Composites," NASA TM 104104, 1991. 
[10] Mirdamadi, M., and Johnson, W. S., "Prediction of Stress-Strain Response of SCS6/Timetal-21S Subjected to the Hypersonic Flight Profile" NASA TM 109026, 1993.

[11] Lekhnitskii, S. G., Theory of Elasticity of an Anisotropic Body, Holden-Day, San Francisco, 1963.

[12] Heywood, R. B., Designing by Photoelasticity, Chapman and Hall, Ltd., London (1952).

[13] Marshall, D. B., Cox, B. N., and Evans, A. G., "The Mechanics of Matrix Cracking in Brittle-Matrix Fiber Composites," Acta Metall., Vol. 33, No. 11, 1985, pp. 20132021.

[14] McCartney, L. N., "Mechanics of Matrix Cracking in Brittle-Matrix Fibre-Reinforced Composites," Proc. R. Soc. Lond., A 409, 1987, pp. 329-350.

[15] McMeeking, R. M., and Evans, A. G., "Matrix Fatigue Cracking in Fiber Composites," Mechanics of Materials, Vol. 9, 1990, pp. 217-227.

[16] Walker, W., "The Effect of Stress Ratio During Crack Propagation and Fatigue for 2024-T3 and 7075-T6 Aluminum," Effects of Environment and Complex Load History on Fatigue Life, ASTM STP 462, American Society for Testing and Materials, 1970, pp. 1-14.

[17] Bigelow, C. A., and Bahei-El-Din, Y. A., "Plastic and Failure Analysis of Composites (PAFAC). LAR-13183, COSMIC, University of Georgia, 1983. 
Table 1. Material Properties:

\section{Material System}

Property

Matrix

Fiber:

Composite:$$
v_{f}
$$

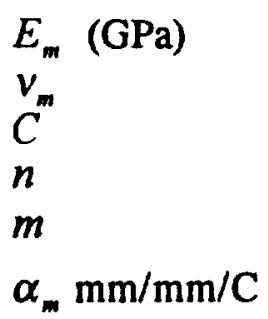

92.4

0.34

$3.8 \mathrm{E}-11$

2.8

0.35

$9.7 \times 10^{-6}$

400.0

0.25

$3.6 \times 10^{-6}$

$[0]_{8}$

0.33

192.2

130.1

$E_{T}(\mathrm{GPa})^{\mathrm{a}}$

$G_{L T}(\mathrm{GPa})^{\mathrm{a}}$

45.9

0.32

$v_{L T}$

$\sigma_{m}^{\text {Therml }}(\mathrm{MPa})^{\mathrm{a}}$

Lay-Up

$v_{f}$

$E_{L}(\mathrm{GPa})^{\mathrm{a}}$

$E_{T}(\mathrm{GPa})^{\mathrm{a}}$

$G_{L T}(\mathrm{GPa})^{\mathrm{a}}$

$v_{L T} \mathrm{a}$

$\sigma_{m}^{\text {Therm }}(\mathrm{MPa})^{\mathrm{a}}$ $202.0^{\mathrm{b}}$

$[0 / 90]_{\mathrm{s}}$

0.35

168.4

168.4

47.4

0.25

$183.8^{b}$
116.0

0.34

$5.5 \mathrm{E}-11$

2.5

0.35

$8.6 \times 10^{-6}$

400.0

0.25

$3.6 \times 10^{-6}$

$[0 / 90]_{s}$

0.36

188.4

188.4

58.1

0.26

$221.9^{c}$

$[0 / 90]_{2 \mathrm{~s}}$

0.38

192.9

192.9

59.3

0.26

$230.5^{\mathrm{c}}$

a Predicted using VISCOPLY [9] based on constituent properties

b Axial ,thermal residual stress in matrix in $0^{\circ}$ plies for cool-down from $555^{\circ} \mathrm{C}$

c Axial ,thermal residual stress in matrix in $0^{\circ}$ plies for cool-down from $620^{\circ} \mathrm{C}$ 


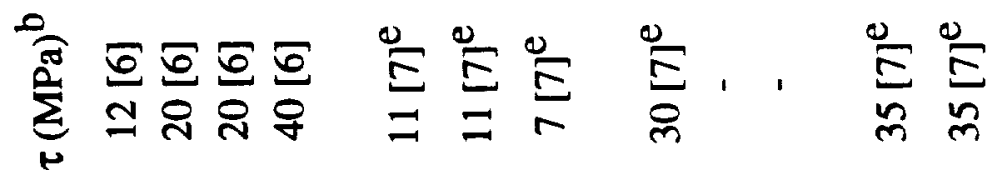

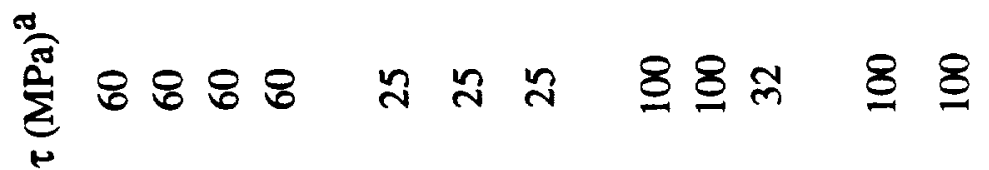

o

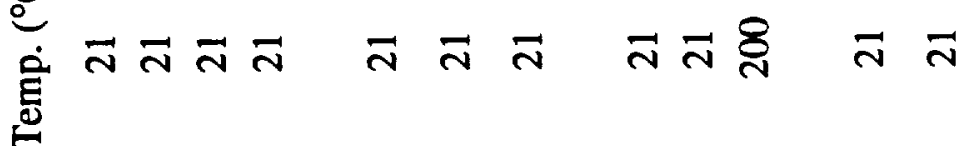

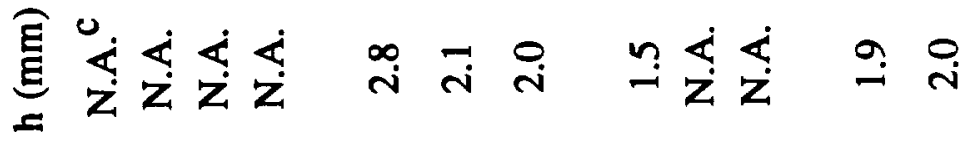

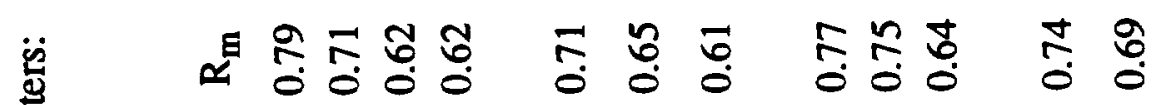

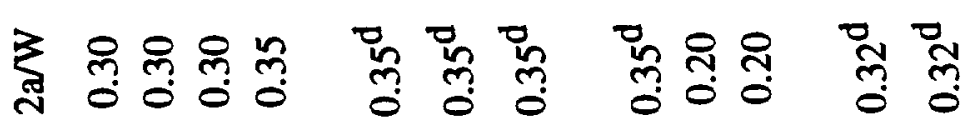

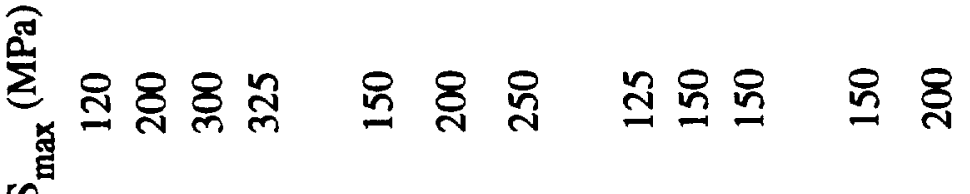

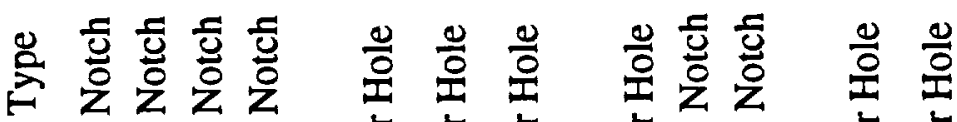

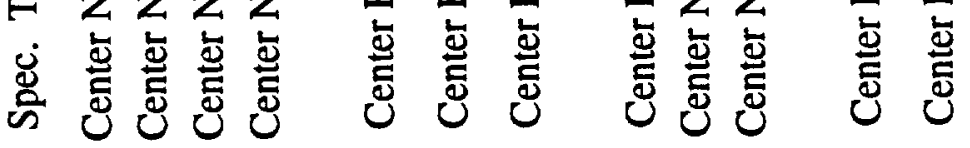

공

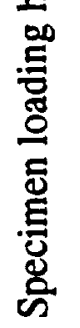

i

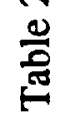

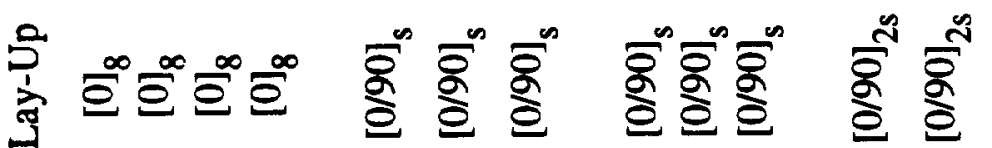
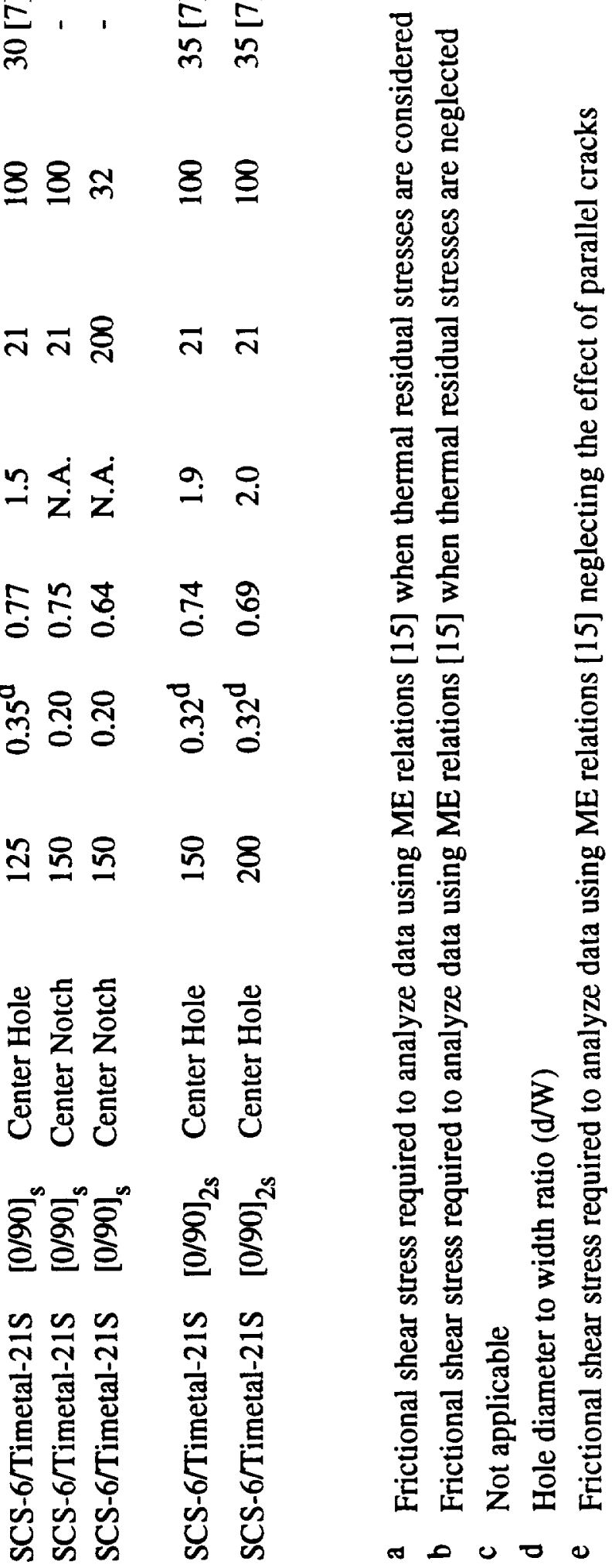


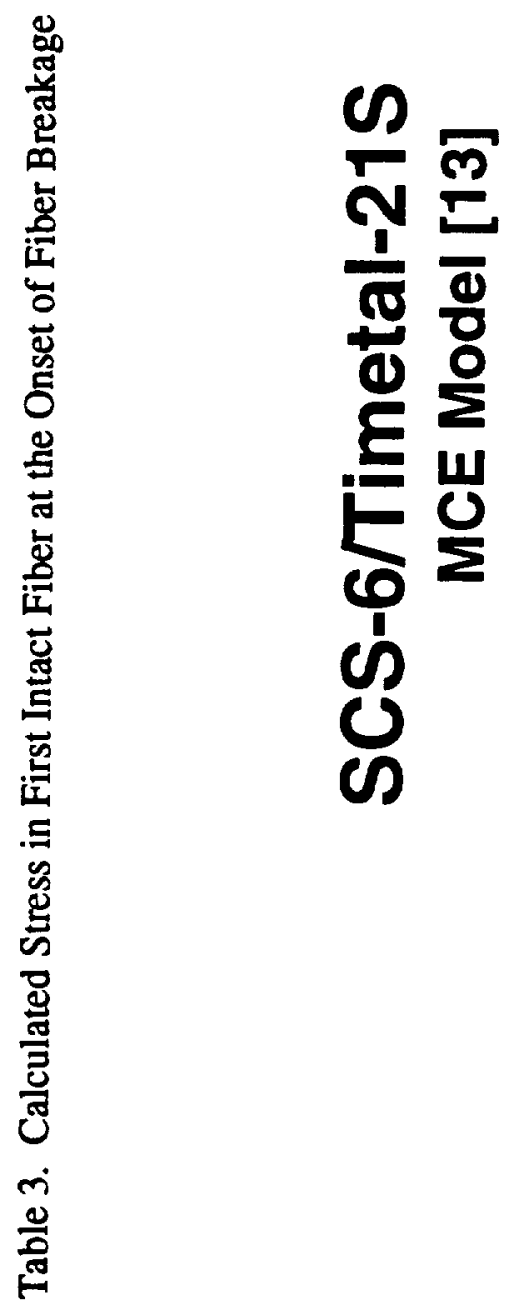

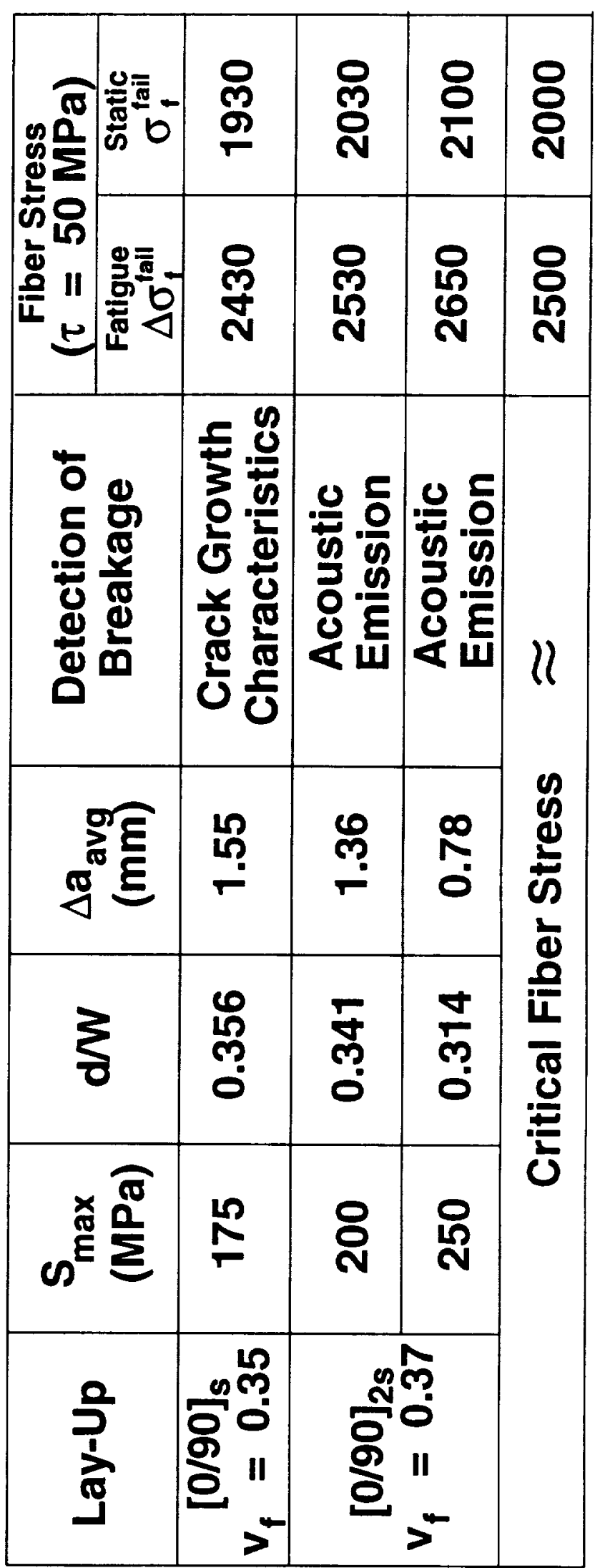




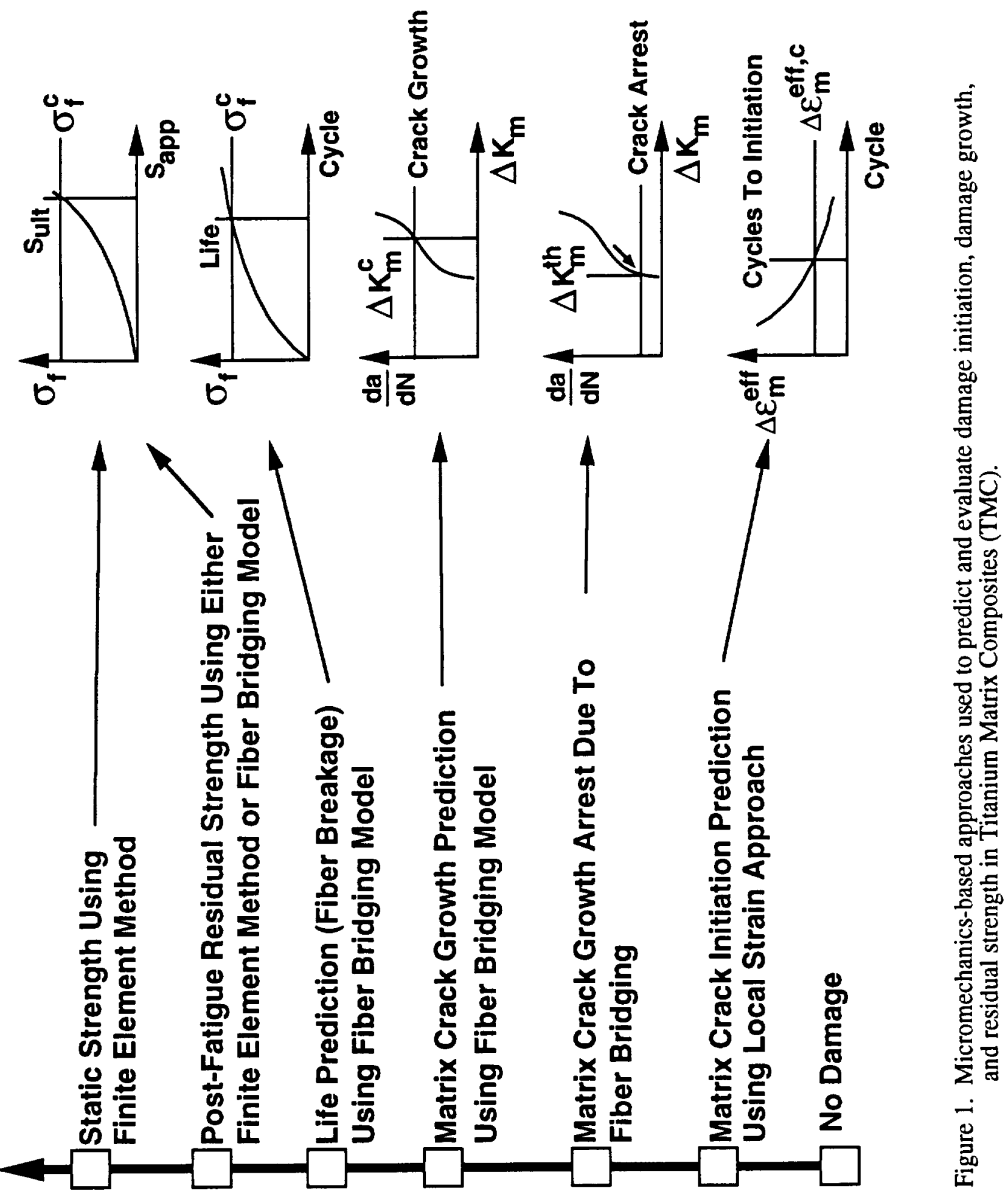




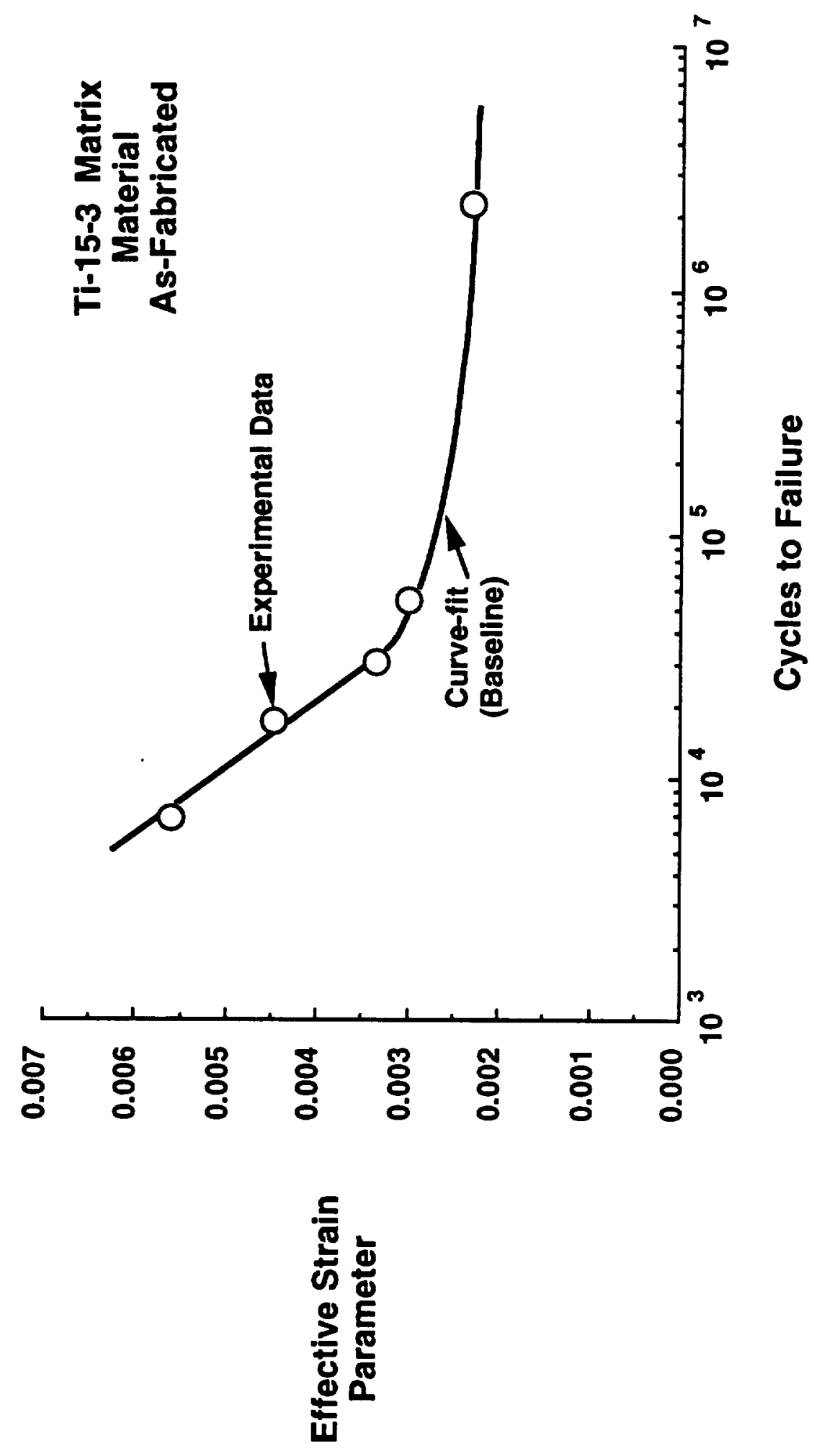

ఏ 


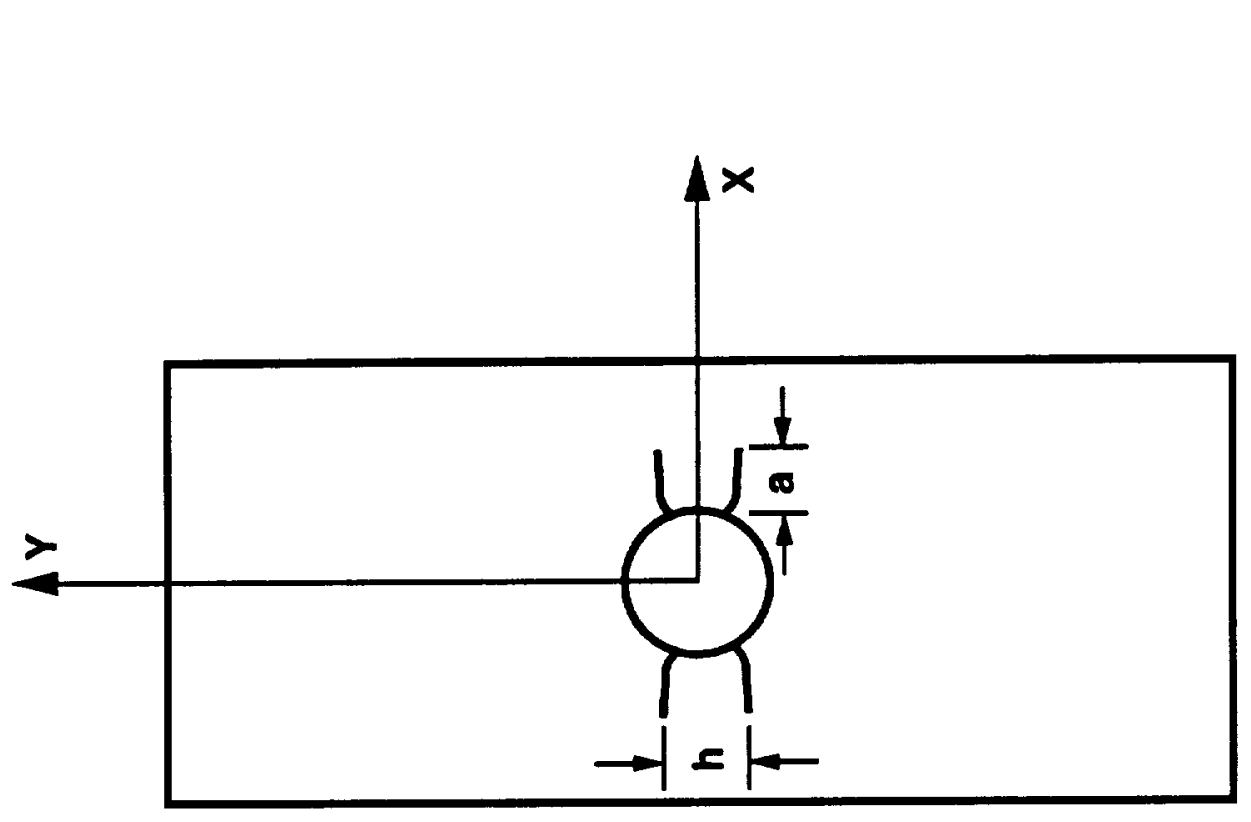

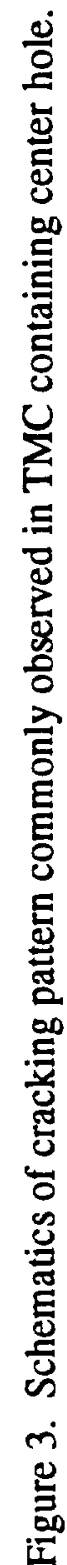



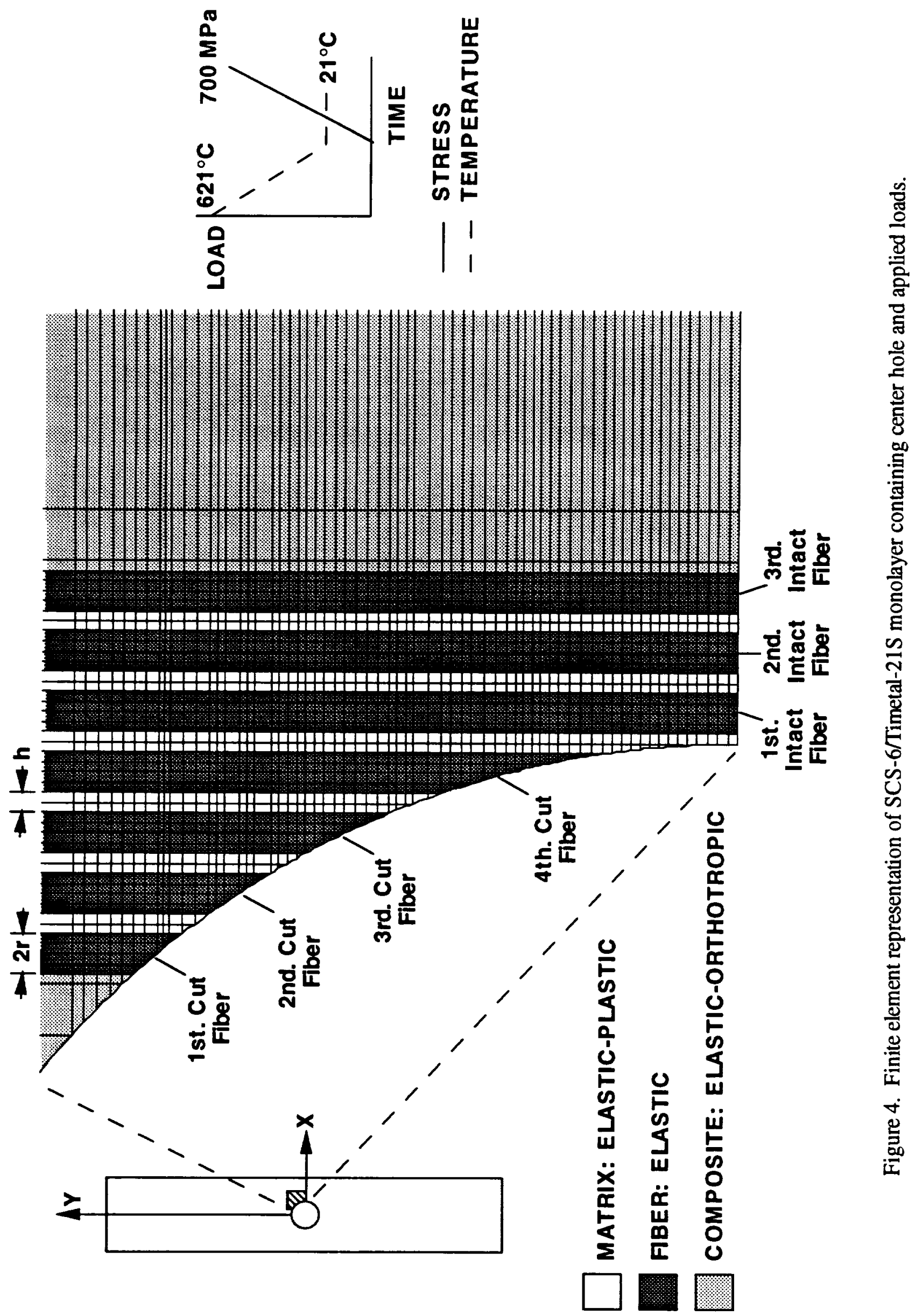


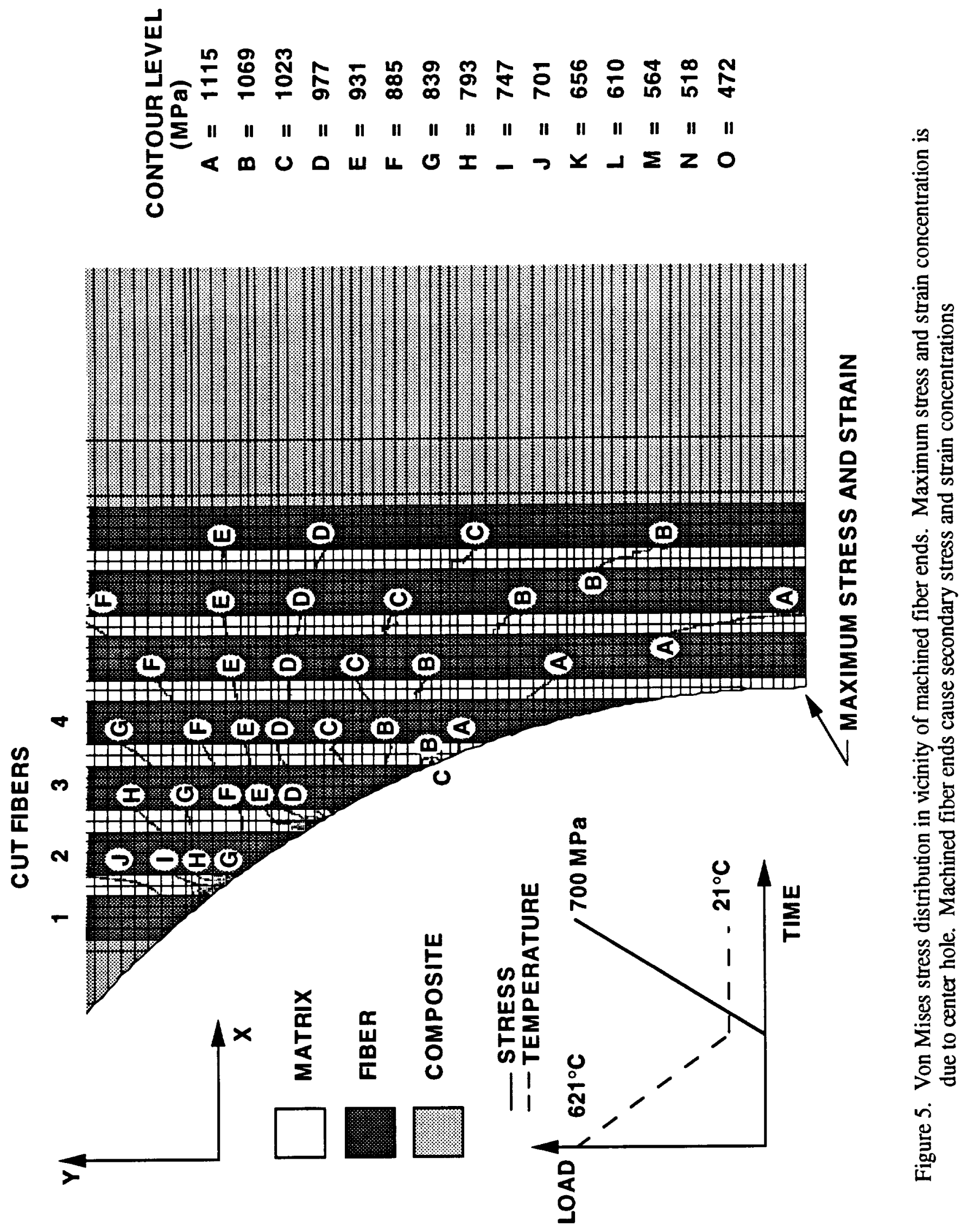




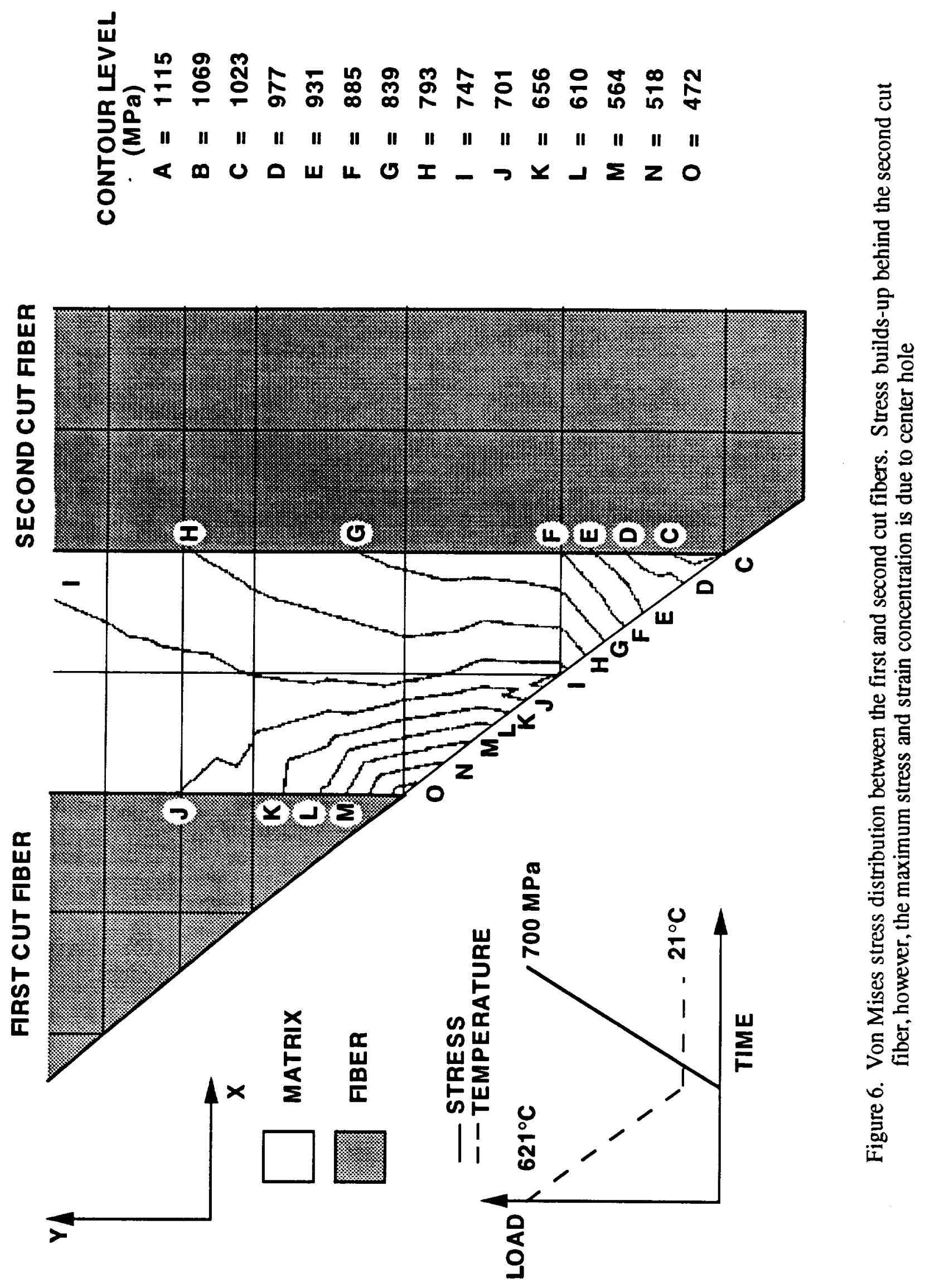




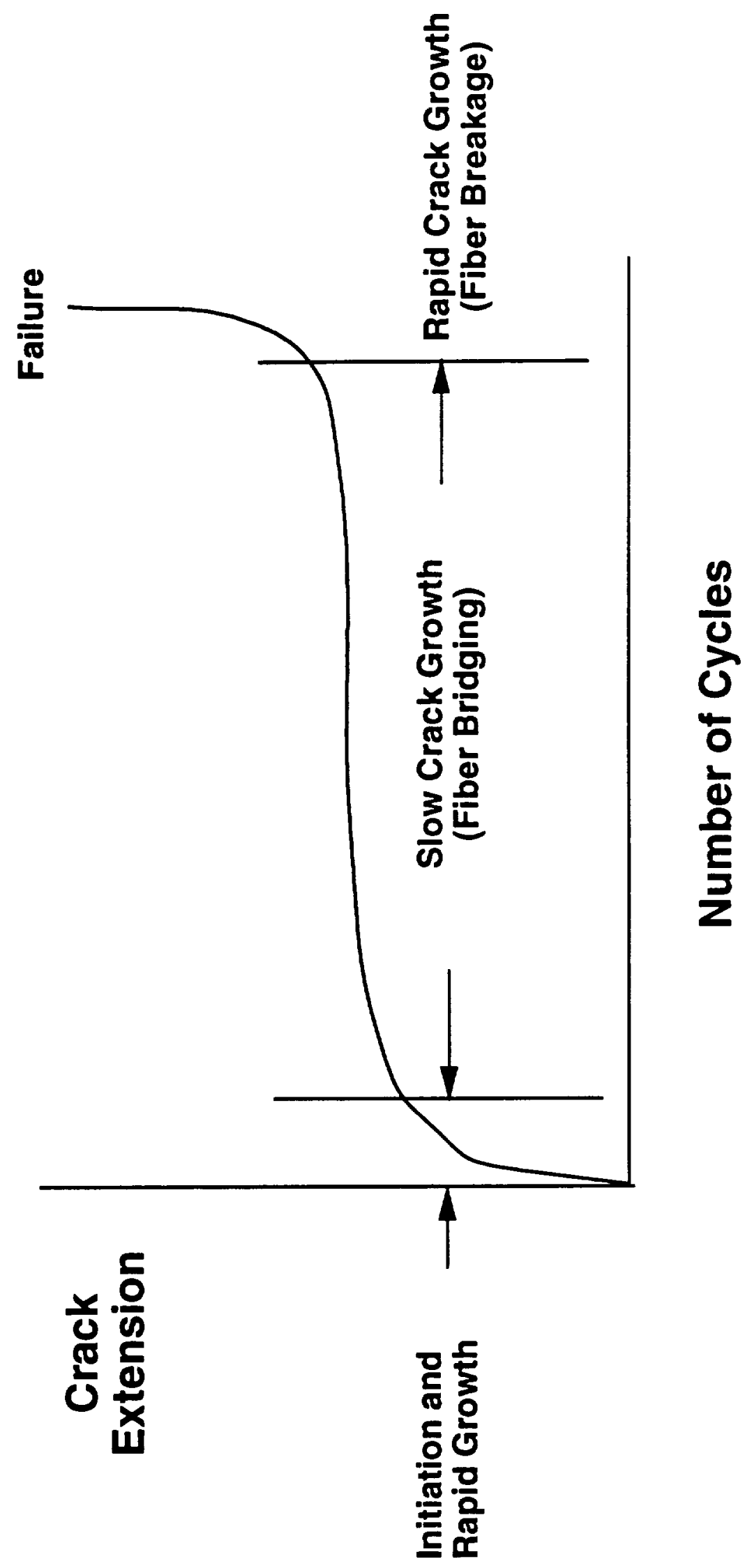

胥

$\stackrel{\dot{I}}{ }$

is

نํํำ

¿

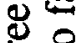

롤

긍

卷

흔

总

บำ

을

$\sum$

$E \dot{0}$

둠

ญ

兘

응

0

능

든

옹 층

ن

5

हี

응

吉总

\%5

苂 금

हิ

들 몽

гं

壱 


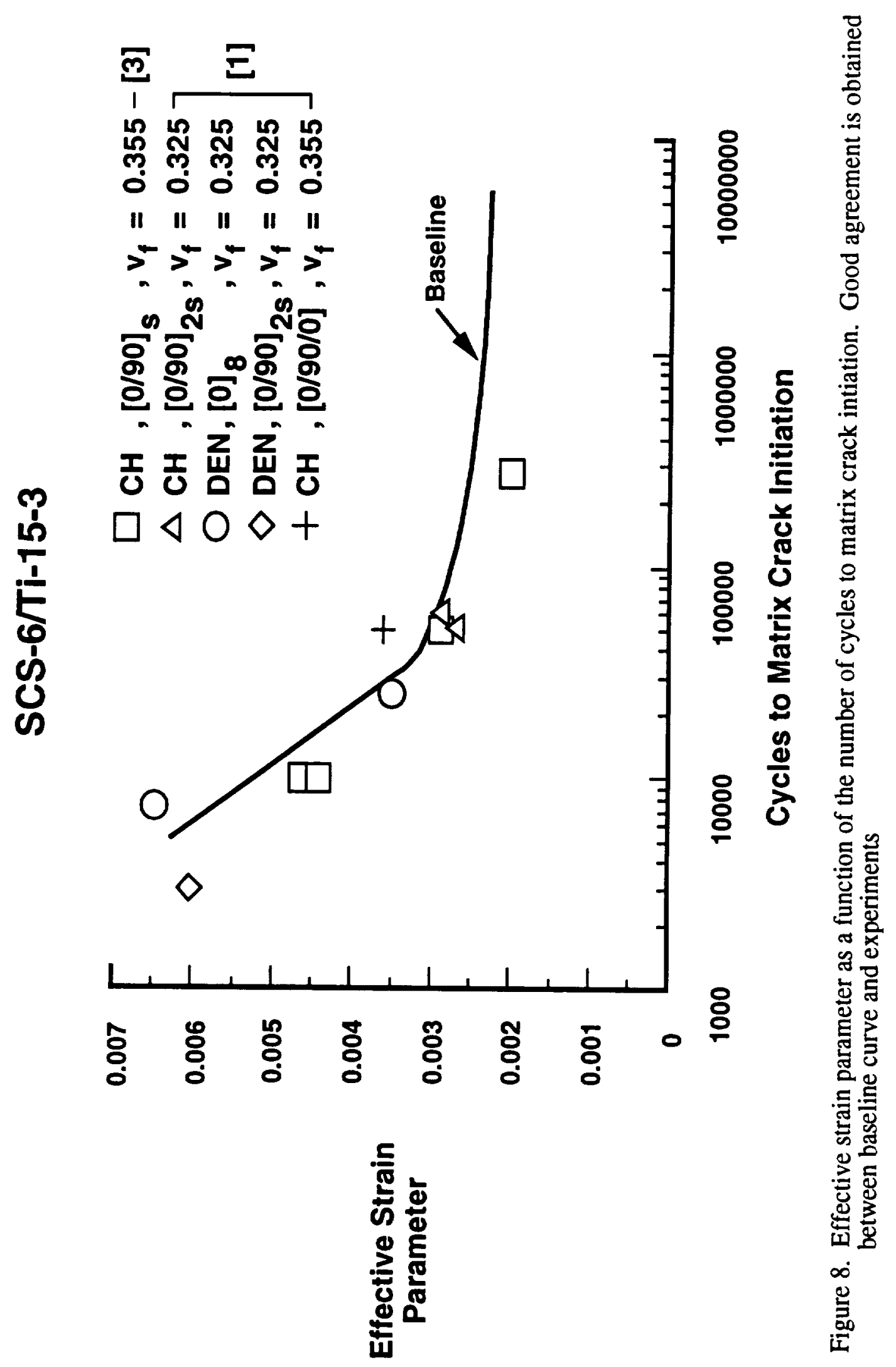




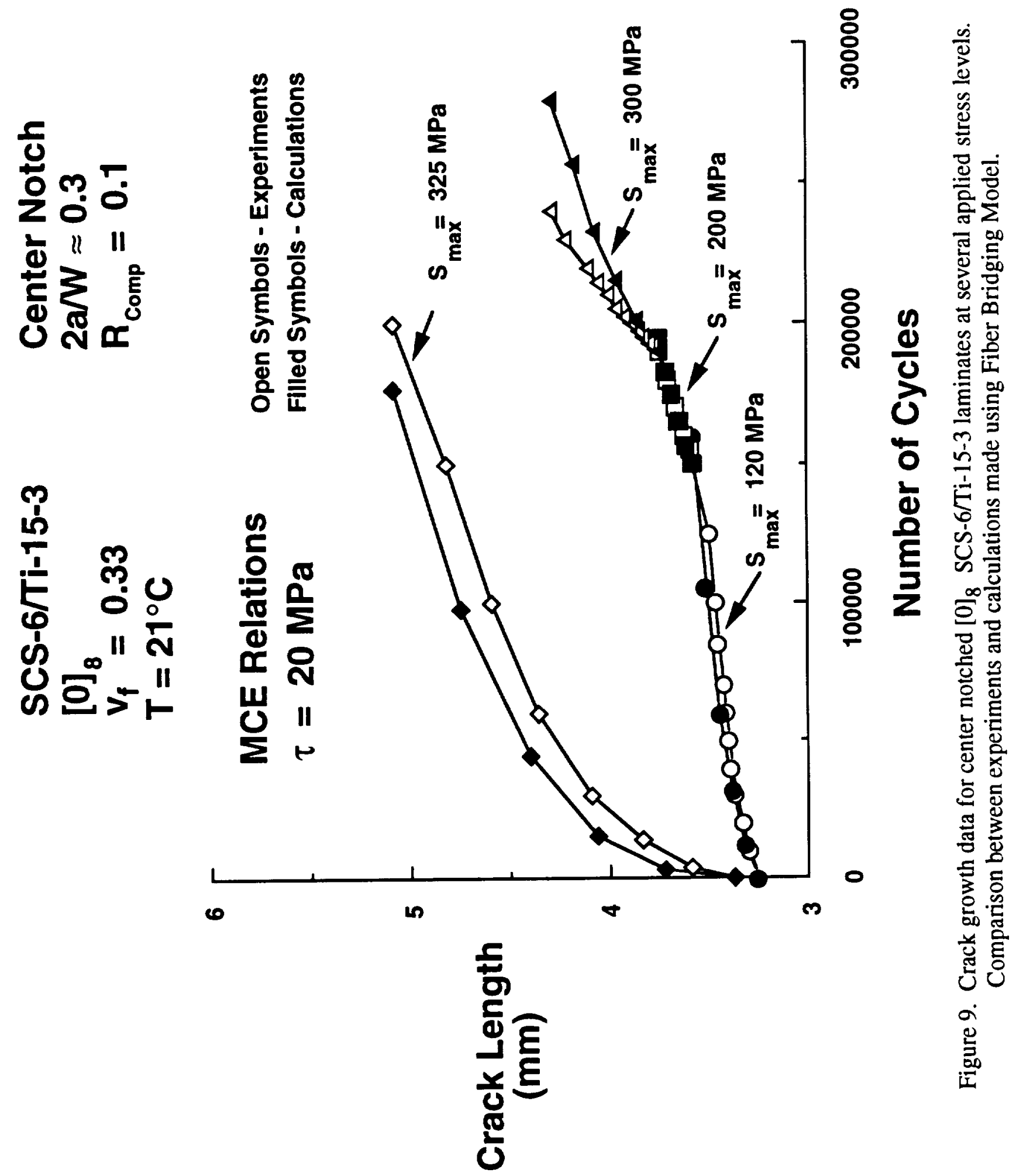




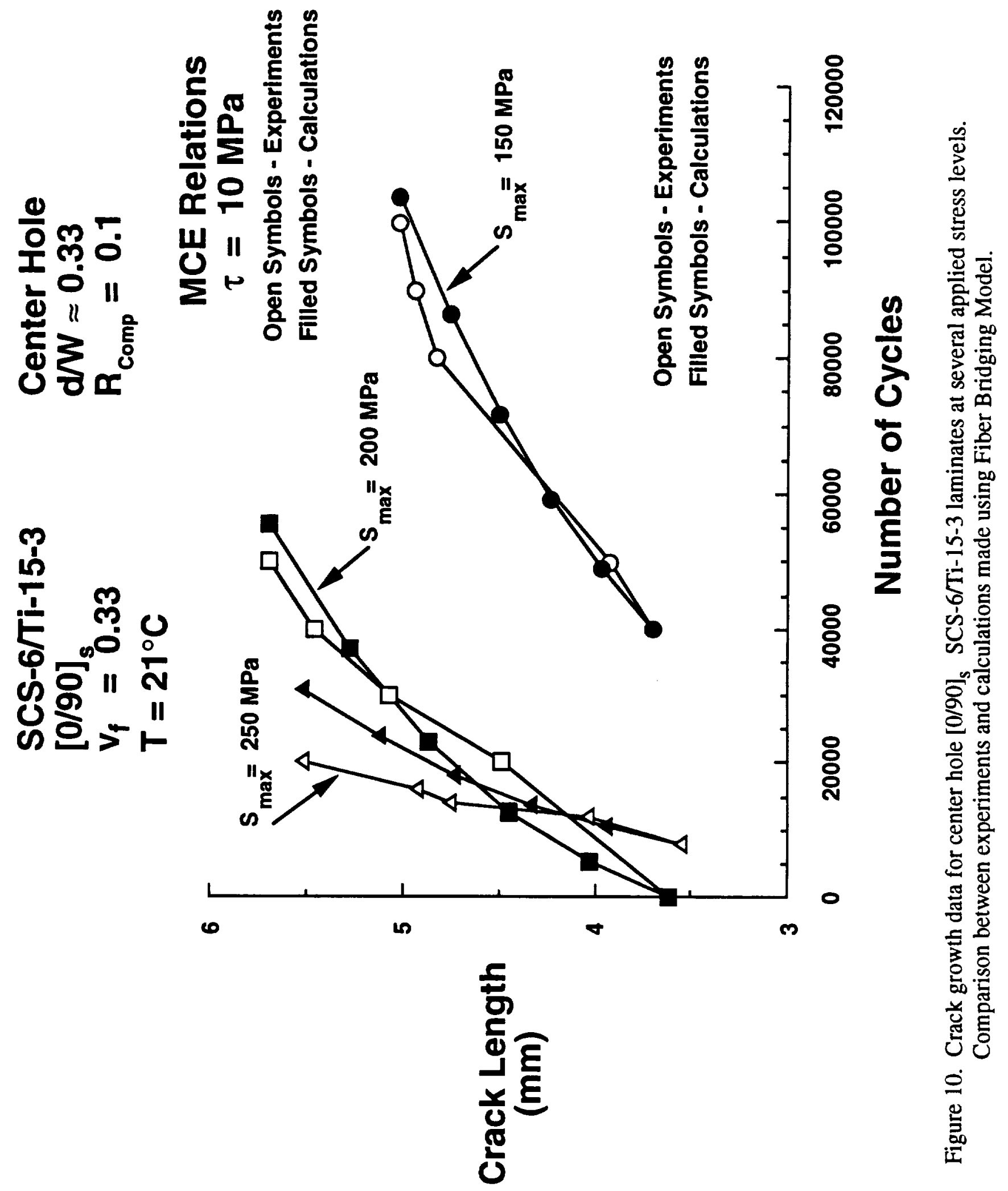



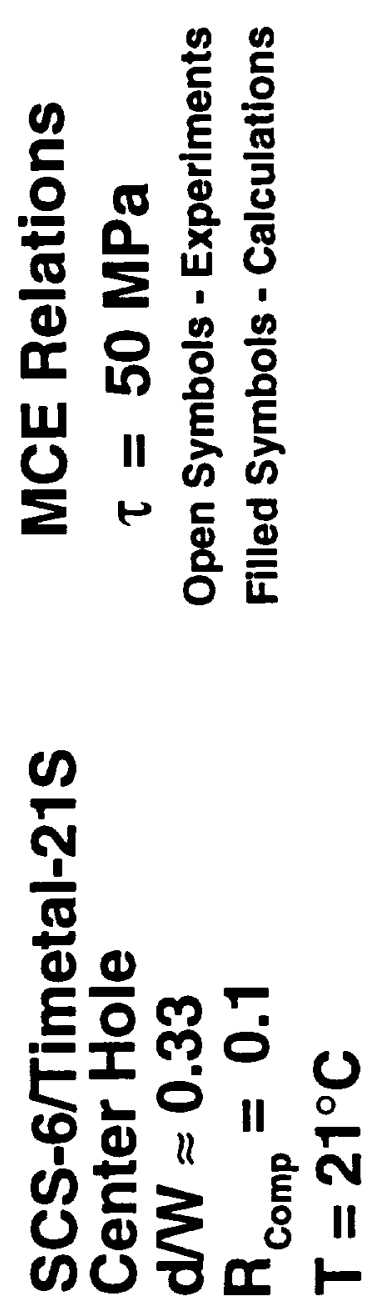

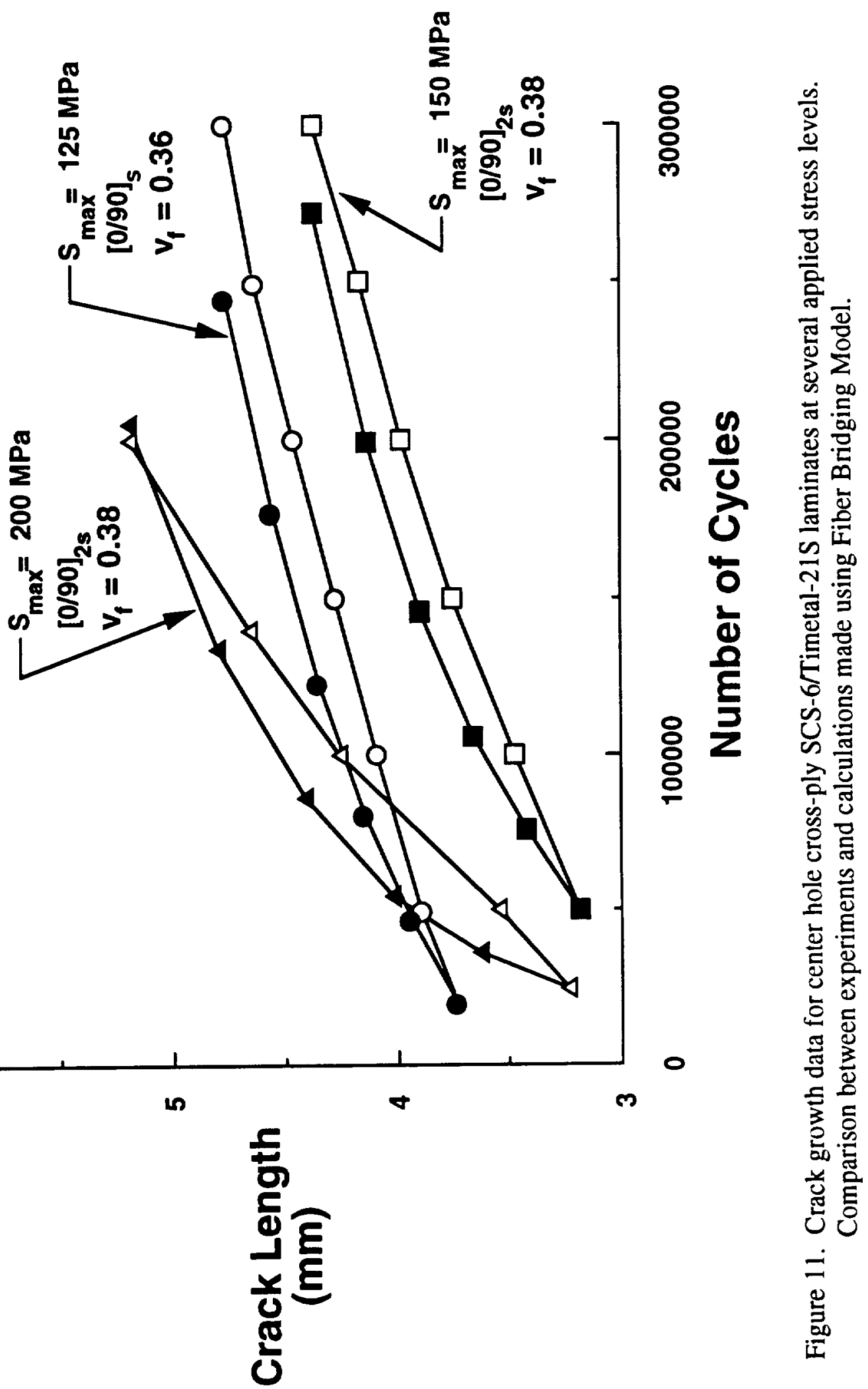




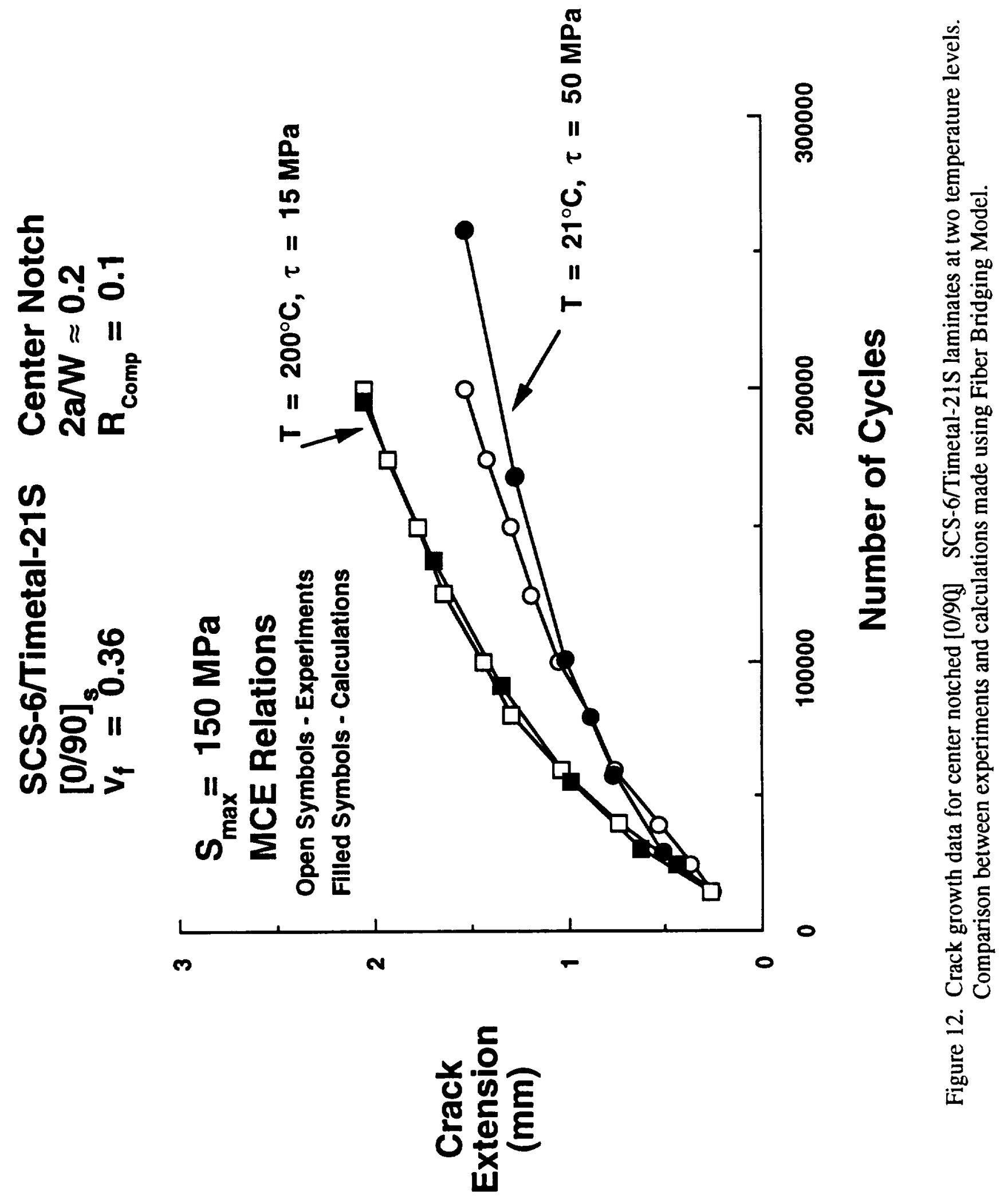




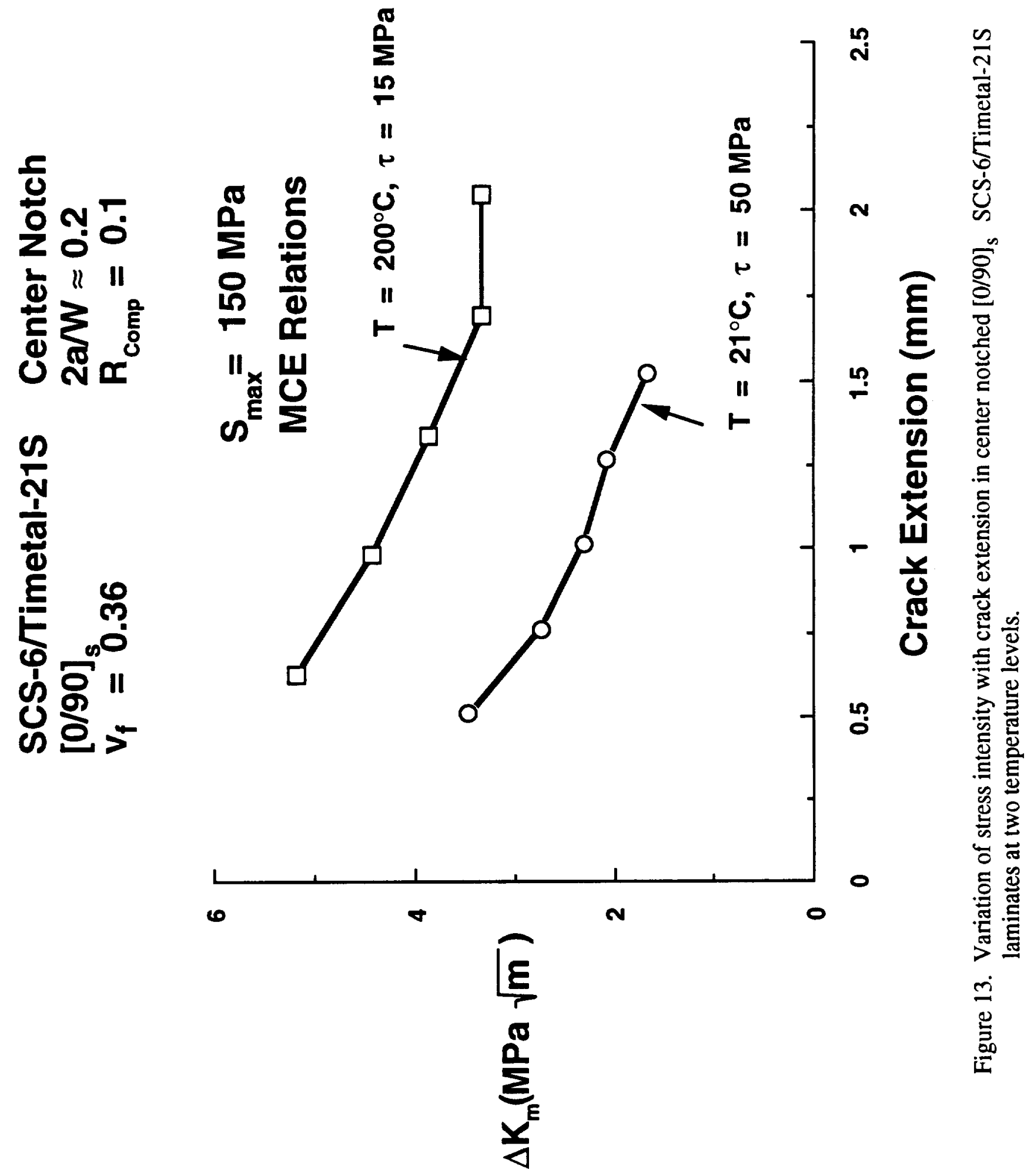




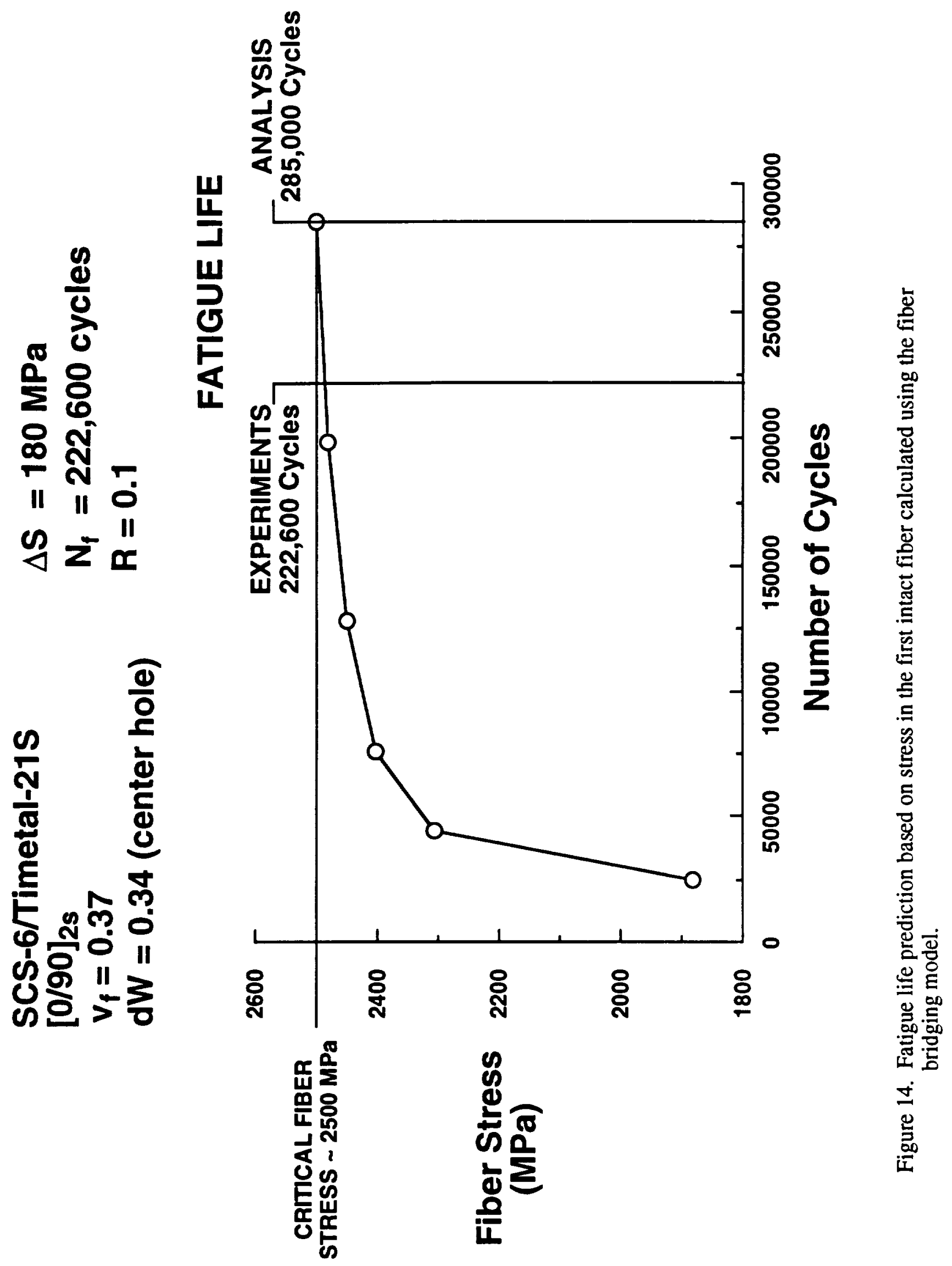




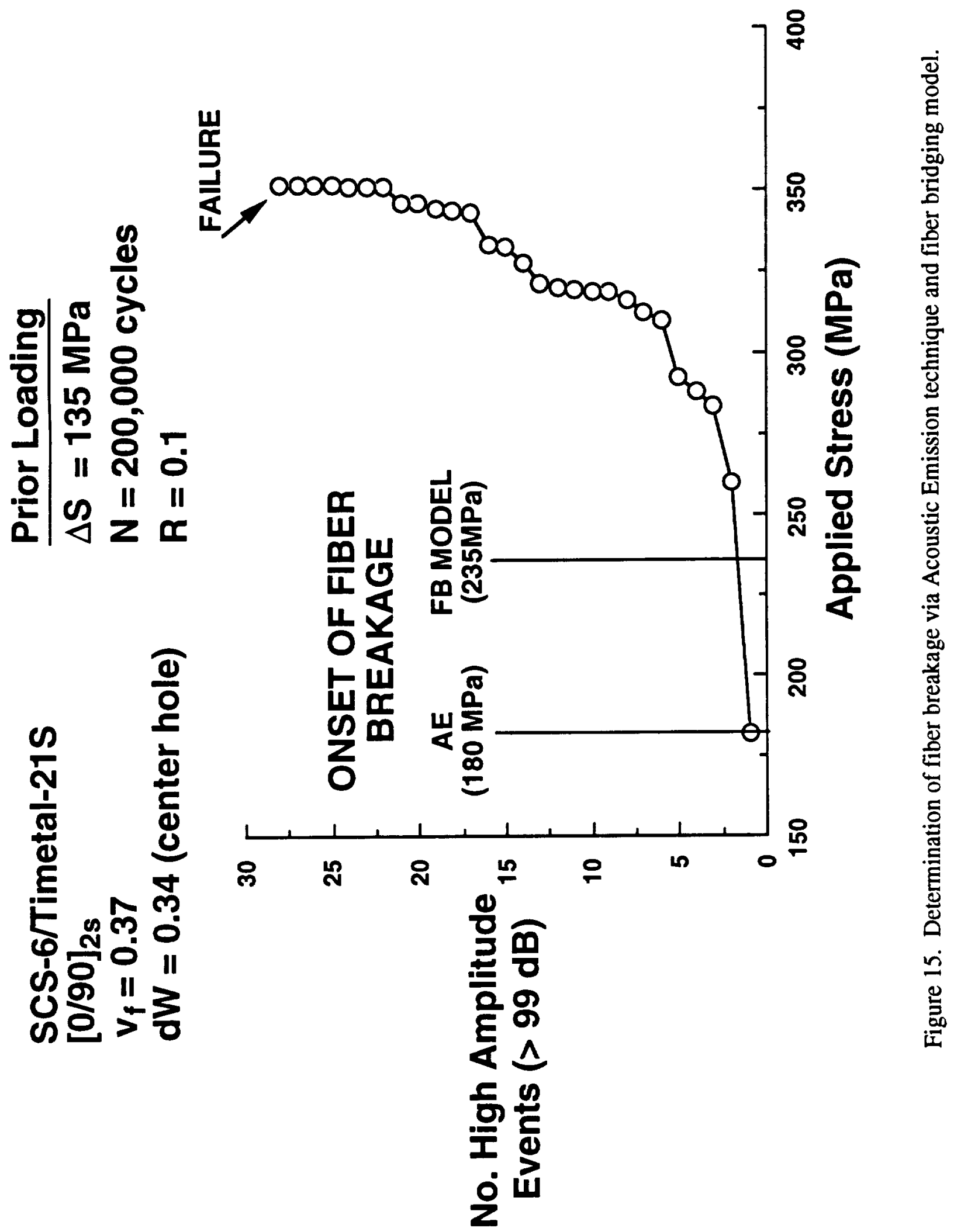




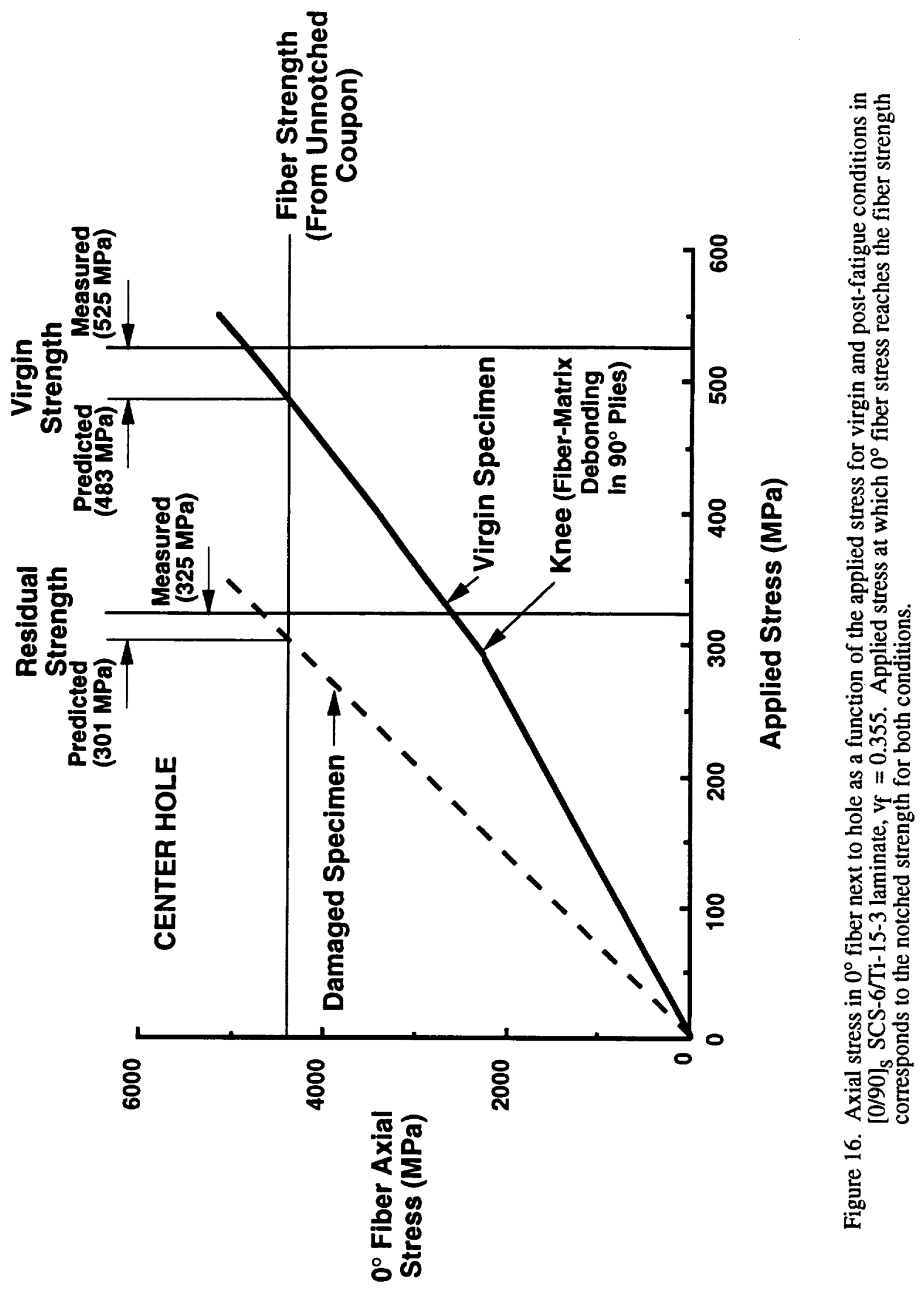





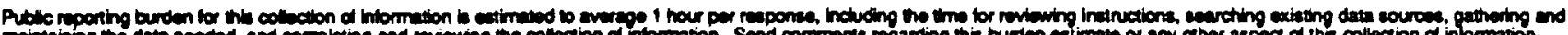

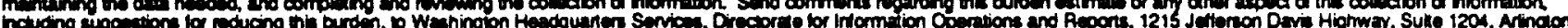

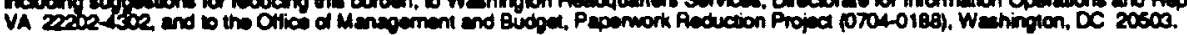

\begin{tabular}{|l|l|l}
\hline 1. AGENCY USE ONLY (LaAvo blank) & $\begin{array}{l}\text { 2. AEPORT DATE } \\
\text { July } 1994\end{array}$ & $\begin{array}{l}\text { 3. REPORT TYPE AND DATES COVERED } \\
\text { Technical Memorandum }\end{array}$ \\
\hline
\end{tabular}

4. TITLE AND SUBTITLE

A Methodology to Predict Damage Initiation, Damage Growth and Residual Strength in Titanium Matrix Composites
5. FUNDING NUMBERS

WU 505-63-50-04

\section{AUTHOR(S)}

J. G. Bakuckas, Jr. and W. S. Johnson

7. PERFORMING ORGANIZATION NAME(S) AND ADDRESS(ES)

NASA Langley Research Center

Hampton, VA 23681-0001
8. PERFOAMING ORGANIZATION REPORT NUMBER
9. SPONSORING / MONITOAING AGENCY NAME(S) AND ADDRESS(ES)

National Aeronautics and Space Administration

Washington, DC 20546-0001
10. SPONSORING / MONTOOAING AGENCY AEPORT NUMBER

NASA TM-109135

\section{SUPPLEMENTARY NOTES}

Bakuckas, Jr.: Galaxy Scientific Corporation. Ploasantville, NJ; Johnson: Langley Research Center, Hampton, VA. Presented at the ASTM Symposium on Lile Prediction Methodology for Titanium Matrix Composites, Hiton Head, SC, March 23-24, 1994.

12. DISTRIBUTIONI AVALABILITY STATEMENT
Unclassilied - Unlimited
Subject Category - 24

\section{ABSTRACT (Maximum 200 words)}

In this research, a methodology to predict damage initiation, damage growth, fatigue life and residual strength in titanium matrix composites (TMC) is outlined. Emphasis was placed on micromechanics-based engineering approaches. Damage initiation was predicted using a local effective strain approach. A finite element analysis verified the prevailing assumptions made in the formulation of this model. Damage growth, namely, fiber-bridged matrix crack growth, was evaluated using a fiber bridging (FB) model which accounts for thermal residual stresses. This model combines continuum tracture mechanics and micromechanics analyses yielding stress-intensity factor solutions for fiber-bridged matrix cracks. It is assumed in the FB model that fibers in the wake of the matrix crack are idealized as a closure pressure, and an unknown constant frictional shear stress is assumed to act along the debond length of the bridging fibers. This frictional shear stress was used as a curve fitting parameter to the available experimental data. Fatigue life and post-fatigue residual strength were predicted based on the axial stress in the first intact $0^{\circ}$ fiber calculated using the FB model and a three-dimensional finite element analysis.

\section{SUBJECT TERMS}

Fiber-matrix debonding; Matrix stress intensity factor; Continuum fracture mechanics; Micromechanics; Interfacial frictional shear stress; Discrele-continuum relations

17. SECURITY CLASSIFICATION
OF REPORT
Unclassified

18. SECUAITY CLASSIFICATION
OF THIS PAGE
Unclassified

19. SECURITY CLASSIFICATION
15. NUMBER OF PAGES 43

16. PRICE CODE $\mathrm{AO} 3$ OF ABSTRACT

20. LIMTAATION OF ABSTRACT

OF A

